\title{
Synergism between Corynebacterium and Streptococcus sanguinis reveals new interactions between oral commensals
}

\author{
Puthayalai Treerat $^{1} \cdot$ Ulrike Redanz $^{1} \cdot$ Sylvio Redanz ${ }^{1,4} \cdot$ Rodrigo A. Giacaman ${ }^{2} \cdot$ Justin Merritt $\mathbb{C}^{1,3} \cdot$ Jens Kreth $\mathbb{B}^{1,3}$
}

Received: 1 August 2019 / Revised: 15 January 2020 / Accepted: 23 January 2020 / Published online: 4 February 2020

(c) The Author(s), under exclusive licence to International Society for Microbial Ecology 2020

\begin{abstract}
The oral microbiome engages in a diverse array of highly sophisticated ecological interactions that are crucial for maintaining symbiosis with the host. Streptococci and corynebacteria are among the most abundant oral commensals and their interactions are critical for normal biofilm development. In this study, we discovered that Streptococcus sanguinis specifically responds to the presence of Corynebacterium durum by dramatically altering its chain morphology and improving its overall fitness. By employing gas chromatography-mass spectrometry (GC-MS) analysis, specific fatty acids were identified in $C$. durum supernatants that are responsible for the observed effect. Membrane vesicles (MVs) containing these fatty acids were isolated from $C$. durum supernatants and were able to replicate the chain morphology phenotype in $S$. sanguinis, suggesting MV as a mediator of interspecies interactions. Furthermore, S. sanguinis responds to C. durum lipids by decreasing the expression of key FASII genes involved in fatty acid synthesis. Several of these genes are also essential for the chain elongation phenotype, which implicates a regulatory connection between lipid metabolism and chain elongation. In addition, $C$. durum was found to affect the growth, cell aggregation, and phagocytosis of $S$. sanguinis, revealing a complex association of these species that likely supports oral commensal colonization and survival.
\end{abstract}

\section{Introduction}

Recent 16S rRNA sequencing and fluorescence in situ hybridization (FISH) [1] studies have revealed Corynebacterium as a highly abundant genus in supragingival dental plaque and as an indicator of oral health [2-5]. Accordingly, Corynebacterium spp. are substantially

Supplementary information The online version of this article (https:// doi.org/10.1038/s41396-020-0598-2) contains supplementary material, which is available to authorized users.

$\checkmark$ Jens Kreth

kreth@ohsu.edu

1 Department of Restorative Dentistry, School of Dentistry, Oregon Health \& Science University (OHSU), Portland, OR 97239, USA

2 Cariology Unit, Department of Oral Rehabilitation, Faculty of Health Sciences, University of Talca, Talca, Chile

3 Department of Molecular Microbiology and Immunology, School of Medicine, Oregon Health \& Science University (OHSU), Portland, OR 97239, USA

4 Present address: Institute for Medical Microbiology, Virology and Hygiene, University Medicine Rostock, Schillingallee 70, 18057 Rostock, Germany decreased in patients with dental caries, periodontitis, and oral lichen planus [6, 7]. Although the Human Oral Microbiome Database includes six oral species within the Corynebacterium genus, only $C$. matruchotii and $C$. durum have been consistently detected at significant levels, which indicates both species as the predominant Corynebacterium taxa within the dental plaque community [4]. Consistent with their role as oral commensals, an intimate relationship seems to exist between Corynebacterium and the pioneer colonizing oral streptococci. FISH studies of intact dental plaques have revealed a specific physical interaction of both species, forming corncob like structures [4]. These structures are part of a higher community organization leading to an environment that supports the subsequent integration of oral anaerobes and ultimately a mature stratified biofilm.

Many oral streptococci are highly abundant pioneer colonizers of the teeth [8-11], providing over $50 \%$ of all transcripts in supragingival dental plaque biofilms $[12,13]$. Oral streptococci can maintain a symbiotic interaction with the host by, at least in part, protecting host epithelial surfaces from invasion/infection by oral pathogens [14]. Of all oral streptococci, S. sanguinis is recognized as one of the most abundant, contributing up to $16 \%$ of the total transcripts detected in supragingival dental plaque [15]. 
Moreover, S. sanguinis is known to release hydrogen peroxide $\left(\mathrm{H}_{2} \mathrm{O}_{2}\right)$, which potently inhibits the growth of many other oral bacteria, especially the pathobionts associated with caries and periodontal diseases $[16,17]$.

For mucosal surfaces harboring diverse groups of microorganisms cohabitating in a symbiotic relationship (like the oral cavity), the bacterial communities generally exhibit numerous sophisticated interspecies interactions to bolster their survival, which in turn benefits the host $[9,18,19]$. Several studies have investigated the complexity of polymicrobial interactions based upon chemical and metabolic exchange among the oral microbiota $[9,20,21]$. Nonetheless, the complexities and interactions among the oral commensal community and the alterations that occur during the shift from health to disease states all remain poorly understood. In this study, we were interested in exploring the interaction between oral commensal corynebacteria and streptococci. We identified a previously unrecognized synergism between $C$. durum and $S$. sanguinis based on the release of fatty acids associated with membrane vesicles (MVs) that influence S. sanguinis physiology. Overall, our findings support the emerging role of commensal Corynebacterium spp. as major drivers of oral biofilm ecology, potentially shaping symbiotic health-associated biofilm communities.

\section{Materials and methods}

\section{Bacterial strains, plasmids, cell culture, and media}

Bacterial strains and plasmids are listed in Supplementary Table 1. C. durum JJ1 was isolated from one subject following an established protocol $[22,23]$ and confirmed by $16 \mathrm{~S}$ rRNA gene sequencing (GenBank accession number MN251472). The protocol for $C$. durum JJ1 isolation was approved by the OHSU institutional IRB, study number STUDY00016426. Cells were routinely grown aerobically as static cultures $\left(5 \% \mathrm{CO}_{2}\right)$ at $37^{\circ} \mathrm{C}$ in Brain Heart Infusion medium (Bacto BHI; Becton Dickinson \& Co., Sparks, MD, USA) or on BHI agar plates as well as in an anaerobic chamber $\left(90 \% \mathrm{~N}_{2}, 5 \% \mathrm{CO}_{2}\right.$, and $\left.5 \% \mathrm{H}_{2}\right)$ when indicated. BHI without glucose [24] (United States Biological, Swampscott, MA, USA) or chemically defined artificial saliva solution medium [25] was used to culture bacterial strains when indicated. Individual and co-cultured bacterial cell suspensions were prepared as described in Supplementary Information. Escherichia coli (E. coli) DH10B was cultured at $37^{\circ} \mathrm{C}$ in Luria-Bertani medium (LB; Lennox, Becton Dickinson \& Co.) with agitation at $200 \mathrm{rpm}$. The following antibiotics were purchased from Sigma-Aldrich (St. Louis, MO, USA) and used when required: spectinomycin ( $300 \mu \mathrm{g}$ $\mathrm{ml}^{-1}$ for $S$. sanguinis strain SK36; $100 \mu \mathrm{g} \mathrm{ml}^{-1}$ for E. coli), erythromycin $\left(5 \mu \mathrm{g} \mathrm{ml}^{-1}\right.$ for SK36). The murine macrophagelike RAW 264.7 cells were purchased from the American Type Culture Collection (ATCC ${ }^{\oplus}$ TIB- $71^{\mathrm{TM}}$ ) and maintained at $37^{\circ} \mathrm{C}$ in Roswell Park Memorial Institute (RPMI) 1640 Medium supplemented with $10 \%$ ( $\mathrm{vol} / \mathrm{vol}$ ) heat-inactivated fetal calf serum and $1 \%$ penicillin/streptomycin (GE Healthcare, WI, USA) in atmosphere of $5 \% \mathrm{CO}_{2}$ and $95 \%$ humidity. RAW 264.7 cells were continuously cultured until passage no. 15 [26]. For transwell co-cultures of $C$. durum and SK36, Transwell ${ }^{\circledR}$ culture inserts $(0.4 \mu \mathrm{M}$ PE membrane, $0.33 \mathrm{~cm}^{2}$ filter area) placed on 24-well plates were used (Corning, NY, USA).

\section{Saliva collection}

Saliva was collected from donors without specific inclusion or exclusion criteria. Immediately after collection, each saliva sample was placed on ice to rest prior to centrifuging at $4000 \mathrm{rpm}$ at $4{ }^{\circ} \mathrm{C}$ for $20 \mathrm{~min}$. The liquid phase was then collected and used for further experiments. The protocol for human subject studies for saliva collection was approved by the OHSU IRB, study number STUDY00015336.

\section{DNA manipulations}

Standard recombinant DNA manipulations were used [27]. Restriction enzymes and other molecular biology reagents were purchased from New England Biolabs (Beverly, MA, USA), Life Technologies (Grand Island, NY, USA), Promega Life Science (Madison, WI, USA), and used according to the manufacturer's instructions. Primers are listed in Supplementary Table 2. PCR products were purified using the Wizard SV gel and PCR clean-up system (Promega). All plasmids were extracted using the Wizard plus SV minipreps DNA purification system (Promega).

\section{Constructions of SK36 $\Delta$ gldA, $\Delta s s a \_0278$, and $\Delta s s a \_0279$ and the complemented mutant strains}

For the construction of mutant strains via allelic exchange, an overlapping PCR strategy was used as described elsewhere [28]. Complementation was achieved using the respective open reading frames with native promoter cloned into plasmid pDL278 [17, 29]. Details can be found in Supplementary Information.

\section{Transposon mutagenesis}

Transposon mutagenesis of SK36 was conducted as described in Supplementary Information. 
RNA isolation, CDNA synthesis, and quantitative RTPCR

RNA extraction was performed as described previously [28, 30, 31]. Details can be found in Supplementary Information.

\section{Free fatty acid analysis}

EnzyChrom ${ }^{\mathrm{TM}}$ Free Fatty Acid Assay Kit (BioAssay Systems, Hayward, CA, USA) was used to measure free fatty acid content in $C$. durum JJ1 supernatants. Details of $C$. durum JJ1 supernatants can be found in Supplementary Information. To further identify the types of free fatty acids, an improved Bligh and Dyer extraction procedure was conducted [32, 33]. Internal standards $\mathrm{C} 11, \mathrm{C} 13$, and C23 saturated fatty acids were added in the samples prior to the derivatization. Fatty acid methyl esters (FAMEs) were extracted into hexane and analyzed by GC-MS. FAMES were separated on a fused silica capillary column (Thermo TR-FAME, $30 \mathrm{~m} \times 0.25 \mathrm{~mm}$ ID $\times 0.25 \mu \mathrm{m}$ film thickness) using an Agilent 7890B GC with a 5977A MSD detector in EI positive mode with a full scan from 50 to $400 \mathrm{~m} / \mathrm{z}$. FAMEs were identified by a comparison of the retention times of commercially available authentic standards (F.A. M.E. Mix, C8-C24; Supelco) and a comparison of the mass spectra with that of the NIST 2014 Library Bundle. All data were normalized to $\mathrm{C} 17$ intensity.

\section{Bacterial MVs isolation and purification}

Bacterial MVs were isolated as described previously with minor modifications [34-36]. In brief, $C$. durum JJ1 was cultured in BHI and BHI without glucose at $37{ }^{\circ} \mathrm{C}$ with $180 \mathrm{rpm}$ agitation overnight. Cells from $1000 \mathrm{ml}$ cultures were pelleted and the supernatants were filtered through 0.45-mm-pore size cellulose acetate filters (VWR International). Filtered supernatants were then concentrated using Vivaspin 20 ultracentrifugation units $(100 \mathrm{kDa}$ MWCO, GE Healthcare) prior to further centrifugation at $15,000 \times g$ $\left(15 \mathrm{~min}, 4^{\circ} \mathrm{C}\right)$ in order to remove cell debris and aggregates. The remaining supernatants were then centrifuged at $100,000 \times g\left(1 \mathrm{~h}, 4^{\circ} \mathrm{C}\right)$ to isolate crude MVs. The supernatants were discarded and the pellets were suspended in $1 \mathrm{ml}$ of $10 \mathrm{mM}$ HEPES $+0.15 \mathrm{M} \mathrm{NaCl}$ for further analysis.

\section{Electron microscopy}

For transmission electron microscopy [37], 5-7 $\mu \mathrm{l}$ of $C$. durum JJ1 supernatants were deposited onto glow discharged carbon formvar 400 Mesh copper grids (Ted Pella, CA, USA) and incubated for $3 \mathrm{~min}$ at room temperature prior to rinsing in $\mathrm{ddH}_{2} \mathrm{O}$ and wicked on Whatman filter paper 1. Afterward, the samples were stained for $60 \mathrm{~s}$ in filtered $1.33 \%(\mathrm{w} / \mathrm{v})$ uranyl acetate prepared in water, wicked, and then air dried. $C$. durum JJ1 supernatant samples were then imaged at $120 \mathrm{kV}$ on a FEI Tecnai ${ }^{\mathrm{TM}}$ Spirit TEM system. The images were acquired as $2048 \times 2048$ pixel, 8-bit gray scale files using the FEI's TEM Imaging and Analysis interface on an Eagle ${ }^{\mathrm{TM}}$ 2K CCD multiscan camera. Images were acquired at 2-4 microns and defocused to improve contrast. For scanning electron microscope (SEM), the biofilm samples were prepared and fixed as published previously [28]. Samples were sputter coated with 10-nm thick carbon (ACE600 coater). Imaging was then performed using a Helios Nanolab 660 dual-beam scanning electron microscope (FEI).

\section{Bacterial survival assay}

Overnight cultures of SK36 and C. durum JJ1 were diluted in order to obtain optical densities of $\mathrm{OD}_{600} \sim 0.05$, as single and dual-species cultures. Culture suspensions were then incubated as static cultures at $37{ }^{\circ} \mathrm{C}$ in $5 \% \mathrm{CO}_{2}$. At the indicated times, cultures were dispersed by vigorous pipetting and vortexing prior to being subjected to serial tenfold dilutions and plating to quantify the bacteria $\left(\mathrm{CFU} \mathrm{ml} \mathrm{l}^{-1}\right.$ ), which can be distinguished on the agar plate due to their morphological differences (Supplementary Information, Figs. S8 and S9). The assay was performed in three biological replicates, and the average number of bacterial cells was then calculated.

\section{Phagocytosis assay in murine macrophage-like RAW 264.7 cells}

To assess the susceptibility to phagocytosis by macrophages, RAW 264.7 cells were chosen as a valid cell line to be used as an in vitro model and have been widely used in other phagocytosis and oral research studies [38-42] due to their phenotypic and functional stability [26]. In brief, RAW 264.7 cells were cultured and phagocytosis assays performed according to a method described previously with some modifications [43]. Subsequently, RAW 264.7 cells were plated at $1.0 \times 10^{5}$ cells/well in 24-well plates (Greiner Bio-One) and cultured overnight at $37^{\circ} \mathrm{C}$ in $5 \% \mathrm{CO}_{2}$. Bacterial strains were cultured in BHI medium and processed according to the preparation protocol in Supplementary Information. Bacterial cell suspensions were added to the RAW 264.7 cell monolayers at an MOI of 10:1 and the infection was then incubated at $37^{\circ} \mathrm{C}$ in $5 \% \mathrm{CO}_{2}$ for 30 , 60, 90, and $120 \mathrm{~min}$. At each time point, infected RAW 264.7 cells were washed and then inoculated into fresh medium supplemented with penicillin-streptomycin (MP Biomedicals, CA, USA) for $2 \mathrm{~h}$ at $37^{\circ} \mathrm{C}$ in $5 \% \mathrm{CO}_{2}$ in order to kill extracellular bacteria. Infected RAW 264.7 cells were then washed, and intracellular bacteria were released by the 
addition of $0.1 \%(\mathrm{v} / \mathrm{v})$ Triton X-100 in PBS. Bacterial cells were dispersed by vigorous pipetting and vortexing (Supplementary Information, Fig. S9). Serial dilutions of the lysates were plated and the numbers of intracellular bacteria (CFU ml ${ }^{-1}$ ) were enumerated.

\section{Fluorescence microscopy}

For microscopic observations, RAW 264.7 cells were plated at $1.0 \times 10^{5}$ cells/well in 24 -well plates containing $13-\mathrm{mm}$ diameter sterile glass coverslips and cultured overnight at $37^{\circ} \mathrm{C}$ in $5 \% \mathrm{CO}_{2}$. Bacterial cell suspensions were prepared as described in Supplementary Information and added to RAW 264.7 cell monolayers at an MOI of 10:1 and then incubated at $37^{\circ} \mathrm{C}$ in $5 \% \mathrm{CO}_{2}$ for $30,60,90$, and $120 \mathrm{~min}$. At the indicated time points post infection (p.i.), the infected RAW 264.7 cells were washed and replenished with fresh RPMI containing penicillin-streptomycin to kill extracellular bacteria for $2 \mathrm{~h}$ at $37^{\circ} \mathrm{C}$ in $5 \% \mathrm{CO}_{2}$. Afterward, wells were washed and fixed with $4 \%$ paraformaldehyde. Fixed cells were stained with phalloidin-tetramethylrhodamine B isothiocyanate (Sigma-Aldrich) at a dilution of 1:200 for $1 \mathrm{~h}$ for labeling filamentous actin. Following washes, the wells were further incubated with DAPI according to the manufacturer's guidelines (Invitrogen). Coverslips were mounted on glass slides with ProLong ${ }^{\mathrm{TM}}$ Glass Antifade Mountant (Invitrogen). Slides were imaged using a Zeiss LSM 780 Inverted Confocal Microscope (Carl Zeiss, Germany) with a $63 \times 1.4$ PlanApo oil objective lens.

\section{Autoaggregation assay}

Autoaggregation of SK36 in C. durum JJ1 supernatants was performed as described previously [44]. The absorbance of the culture at $600 \mathrm{~nm}$ was measured at $0 \mathrm{~h}\left(\mathrm{~A}_{0}\right)$ and $8 \mathrm{~h}\left(\mathrm{~A}_{8}\right)$ using a BioSpectrometer ${ }^{\circledR}$ basic (Eppendorf). Bacterial autoaggregation data were expressed as an autoaggregation percentage (Ag $\%)$ and calculated using: $\mathrm{Ag} \%=\left[\left(\mathrm{A}_{0}-\mathrm{A}_{8}\right) / \mathrm{A}_{0}\right] \times 100$ [44].

\section{Statistical analysis}

The statistical significance of the difference between experimental groups was determined by Student's $t$-test (2tailed). $P$ values less than 0.05 were considered significant.

\section{Results}

\section{Species-specific interaction between $C$. durum and SK36}

The spatial organization of streptococci and corynebacteria within in situ biofilms [4] suggests interspecies cell signaling and metabolic communications likely occur between them. To study such interactions, a clinical isolate of $C$. durum JJ1 was co-cultured with S. sanguinis SK36. Control monocultures of $C$. durum JJ1 and SK36 exhibited filamentous aggregates for $C$. durum $\mathrm{JJ} 1$ and short bacterial chains for SK36, whereas dual-species co-cultures revealed a dramatic increase in SK36 chain length (Fig. 1). The elongated SK36 cell chain phenotype could be repeated in transwell culture plates (Fig. S1) as well as with $C$. durum JJ1 supernatants suggesting contact independent mechanisms are responsible for the phenotype. Chain elongation was also observed with supernatants from C. matruchotii ATCC14266 and $C$. durum ATCC33822, but not $C$. glutamicum ATCC 13032 (Fig. 2a). Chain elongation was also observed with the endocarditis isolate S. sanguinis 133-79 (Fig. 2b) and eight distinct S. sanguinis strains (Fig. S2), while $S$. gordonii DL1 $(S g), S$. parasanguinis $(S p), S$. mutans UA159 (Sm), and S. oralis J22 (So) showed no obvious differences suggesting a species-specific interaction between $S$. sanguinis and $C$. durum through a diffusible compound (Fig. 2c).

\section{Effect of fatty acids on S. sanguinis chain elongation}

Initial characterizations of the $C$. durum $\mathrm{JJ} 1$ diffusible signal excluded a proteinaceous origin (Fig. S3). Therefore, filtered $C$. durum JJ1 supernatants were treated with chloroform to separate the water soluble/insoluble components. The aqueous phase of the $C$. durum JJ1 supernatant failed to induce the SK36 elongated phenotype (data not shown), suggesting a possible role of C. durum JJ1 lipid(s) in SK36 chain elongation. Employing a quantitative colorimetric fatty acid assay, we next confirmed the presence of fatty acids in $C$. durum $\mathrm{JJ} 1$ supernatants grown in a fatty acid free chemically defined medium [25] (Fig. 3a). The free fatty acid content in mixed C. durum JJ1/SK36 cultures was significantly increased when compared with the individual cultures $(P<0.0001)$ (Fig. 3a), implying a synergistic effect on fatty acid production and/ or an accumulation of free fatty acids produced by both $C$. durum JJ1 and SK36.

We next identified the types of fatty acids present in $C$. durum JJ1 supernatant. Palmitic (C16:0), stearic (C18:0), and oleic (C18:1) acids were increased in the supernatant in comparison with the medium control (Fig. 3b). Media containing palmitic, stearic, and/or oleic acid(s) alone or in combination with each other were prepared and evaluated for their ability to induce SK36 chain elongation. Most of the tested media were able to induce the elongation phenotype, and the chain length was $\sim 7$ times longer than the medium control $(P<0.0001)$ (Fig. 3c). However, medium supplemented with only palmitic or stearic acid exhibited no significant differences from the control (Fig. 3c). 
Fig. 1 Effect of $C$. durum JJ1 [1] on $S$. sanguinis SK36 (SK36) chain morphology. SK36 was cultured with $C d$ overnight at $37^{\circ} \mathrm{C}$ in a $5 \% \mathrm{CO}_{2}$ atmosphere. Cell morphology was examined and imaged using an Olympus IX73 inverted microscope. The pictures are representative of three independent experiments. Scale bars indicate $50 \mu \mathrm{m}$.
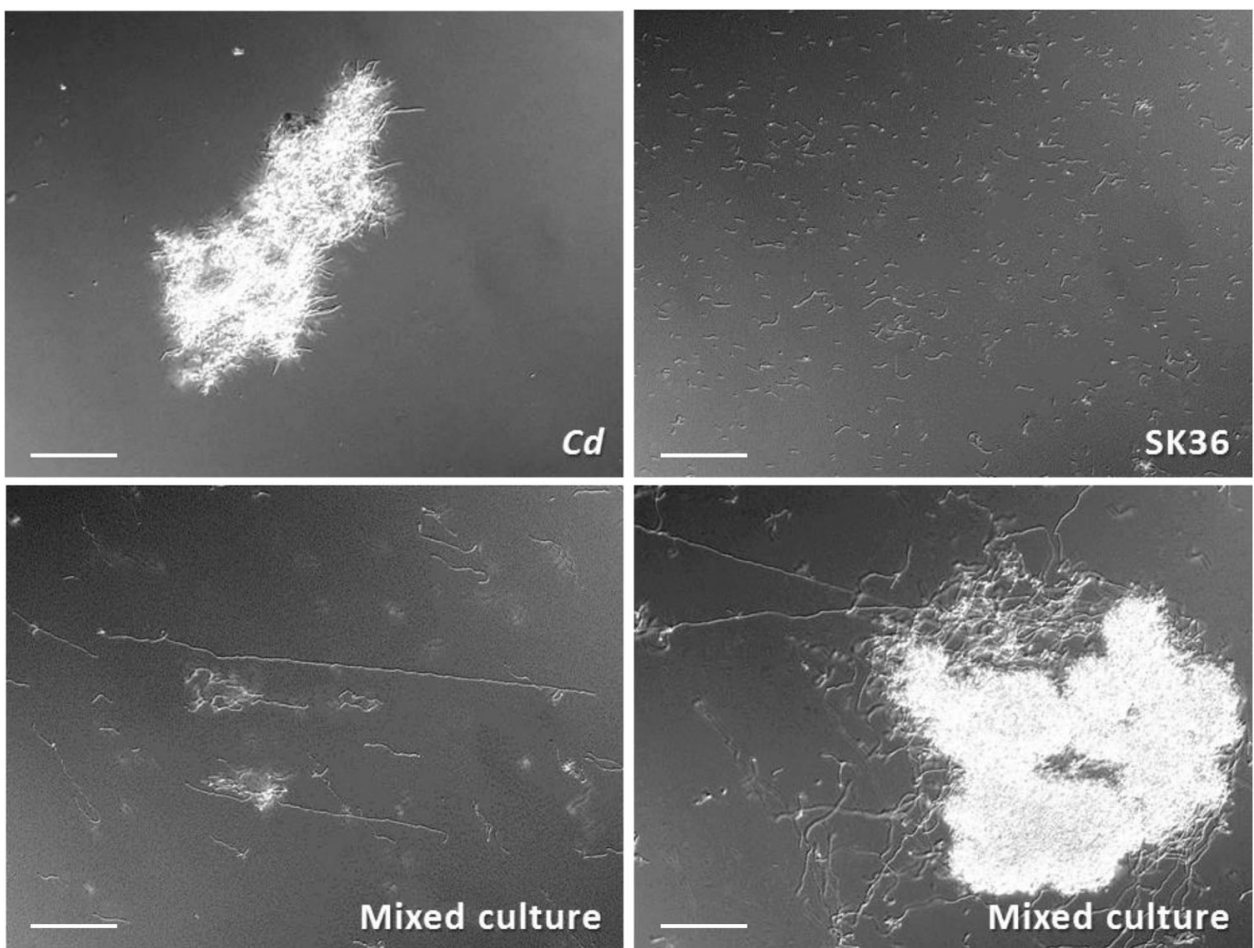

Based upon previous gene regulation studies of streptococcal type II fatty acid synthesis (FASII) [45-47], we suspected that SK36 can utilize lipid molecules from the environment and reduce its own fatty acid synthesis. Accordingly, preexisting SK36 transposon mutants in the FASII pathway genes $f a b H$ and $a c p P$ were examined for their chain length phenotypes. Both genes of the streptococcal FASII pathway have been previously reported as important in bacterial lipid metabolism and membrane homeostasis [45-49]. Indeed, Tn insertions in $\mathrm{fabH}$ and acpP genes caused an elongated chain phenotype (Fig. 3d) suggesting a regulatory connection between fatty acid biosynthesis and chain elongation.

\section{Role of glycerol dehydrogenase ( $g / d A)$ and other genes in SK36 chain elongation}

Streptococcal cell morphology and cellular chain length can be affected by a wide range of environmental and genetic factors, contributing to their physical behaviors, and interactions with other bacteria and the host $[44,50]$. We next examined if the elongated phenotype induced by $C$. durum $\mathrm{JJ} 1$ would affect the expression of genes involved in lipid metabolism and cell division [51, 52], specifically FASII genes ( $f a b G, f a b H$, and SSA_1941), lipid metabolism ( gldA), cell membrane and cell division (divlB, $m r e C$, and $c l s)$ genes. Expression of $f a b G, f a b H$, and a predicted transcriptional regulator ssa_1941 exhibited significantly lower expression than in the BHI control $(P<0.005)$ (Fig. 4a), confirming an effect of an enriched fatty acid environment on FASII gene expression in SK36. Conversely, gldA expression was significantly increased, compared to the BHI control $(P<0.01)$. Expression of $\operatorname{divIB}$ was decreased approximately twofold, while cls gene expression was slightly increased in comparison with the control $(P<0.05)$ (Fig. 4a). Expression of $m r e C$ showed no significant difference (Fig. 4a).

gldA plays a key role in the beginning of fatty acid metabolism [53, 54]. Deletion mutants of gldA, and the predicted gldA regulators SSA_0278 and SSA_0279 as identified by the RegPrecise database [55], were generated. In contrast to the elongated wild type, the chain length of SK36 $\Delta$ gldA, $\Delta$ SSA_0278, and $\Delta$ SSA_0279 did not elongate in the presence of $C$. durum $\mathrm{JJ} 1$ supernatant. All complemented strains exhibited elongated chain lengths similar to the wild-type (Fig. 4b, c). To further verify that both SSA_0278 and SSA_0279 are involved in gldA regulation, expression of gldA in $\Delta$ SSA_0278 and $\triangle$ SSA_0279 was determined after both mutants were treated with $C$. durum JJ1 supernatants. Expression of gldA in the $\Delta$ SSA_0278 and $\Delta$ SSA_0279 was not affected by $C$. durum $\mathrm{JJ} 1$ supernatants, whereas gldA was significantly induced in the wild-type strain (Fig. 4d). This finding confirmed a potentially regulatory effect of $C$. durum JJ1 supernatant on gldA through SSA_0278 and SSA_0279. 
A)

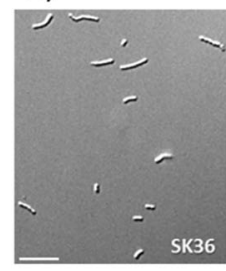

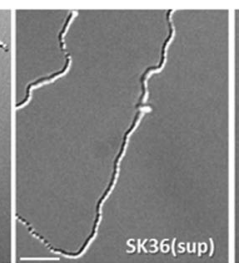
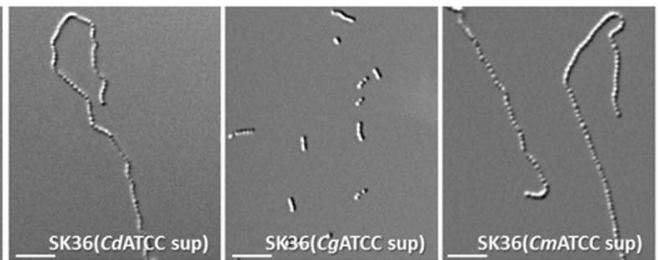

B)

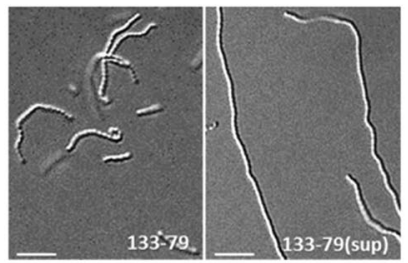

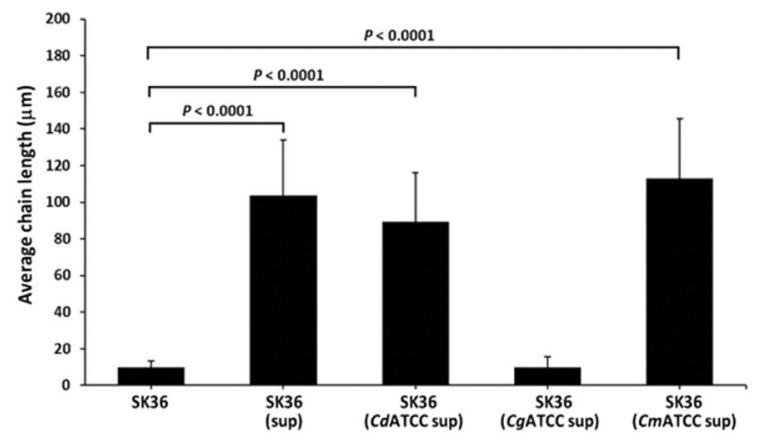

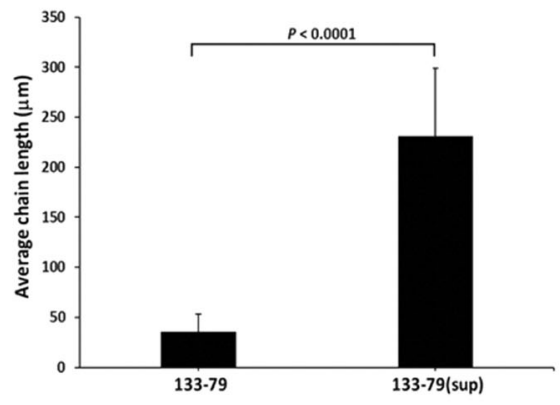

C)
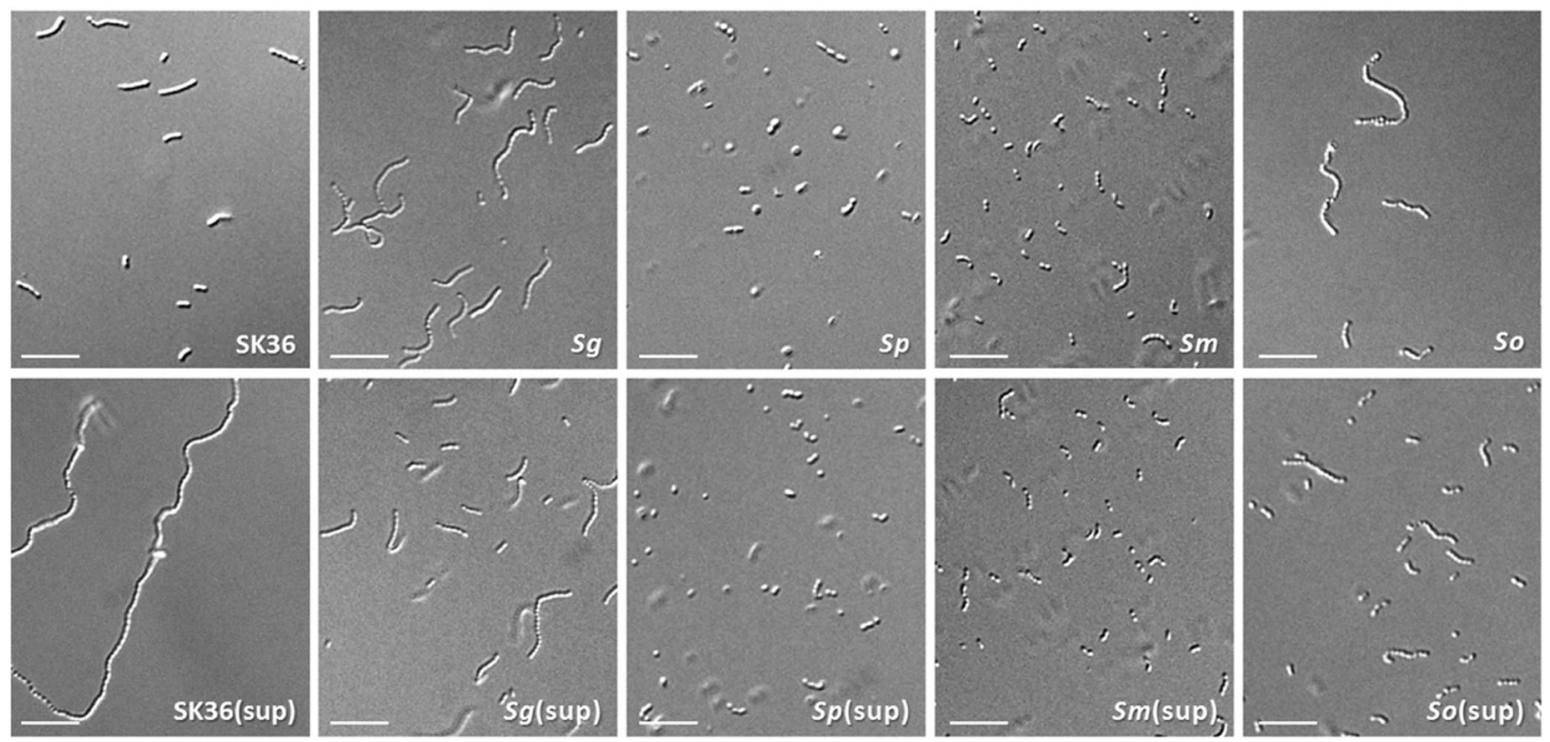

Fig. 2 Strain-specific interactions between Corynebacterium spp. and $S$. sanguinis. a Supernatants collected from the overnight cultures of C. glutamicum ATCC 13032 (CgATCC) and C. matruchotii ATCC14266 (CmATCC) were used to treat SK36 in comparison with those of $C$. durum ATCC33822 (CdATCC) and a $C d$ clinical isolate. b A clinical isolate $S$. sanguinis 133-79, c $S$. gordonii DL1 (Sg), S. parasanguinis (Sp), S. mutans UA159 (Sm), and S. oralis J22 (So) were treated with $C d$ supernatants and then examined for their chain morphologies. For quantification, bacterial chain length was measured from 100 bacterial chains per one biological replicate using ImageJ software [75], and the average chain length $(\mu \mathrm{m})$ was calculated from three biological replicates. Data are presented as the means \pm standard deviations. The pictures are representative of three independent experiments. Scale bars indicate $10 \mu \mathrm{m}$.

\section{Contribution of glucose and lipid metabolism to SK36 chain morphology}

A direct connection between glucose and fatty acid metabolism pathways in both Corynebacterium spp. [56] and Streptococcus spp. [57] has been established. We hypothesized that glucose may impact the production of fatty acids and the chain elongation phenotype. To test this, BHI (BHI), BHI without glucose (BHI w/o), and BHI without glucose supplemented with $0.01 \mathrm{M}$ glucose (BHI glu) were prepared and used to culture $C$. durum JJ1 overnight. The chain length of SK36 cultured in BHI, BHI w/o, and BHI glu, as the controls, showed no significant difference. Interestingly, C. durum JJ1 BHI w/o supernatant was unable 
A)
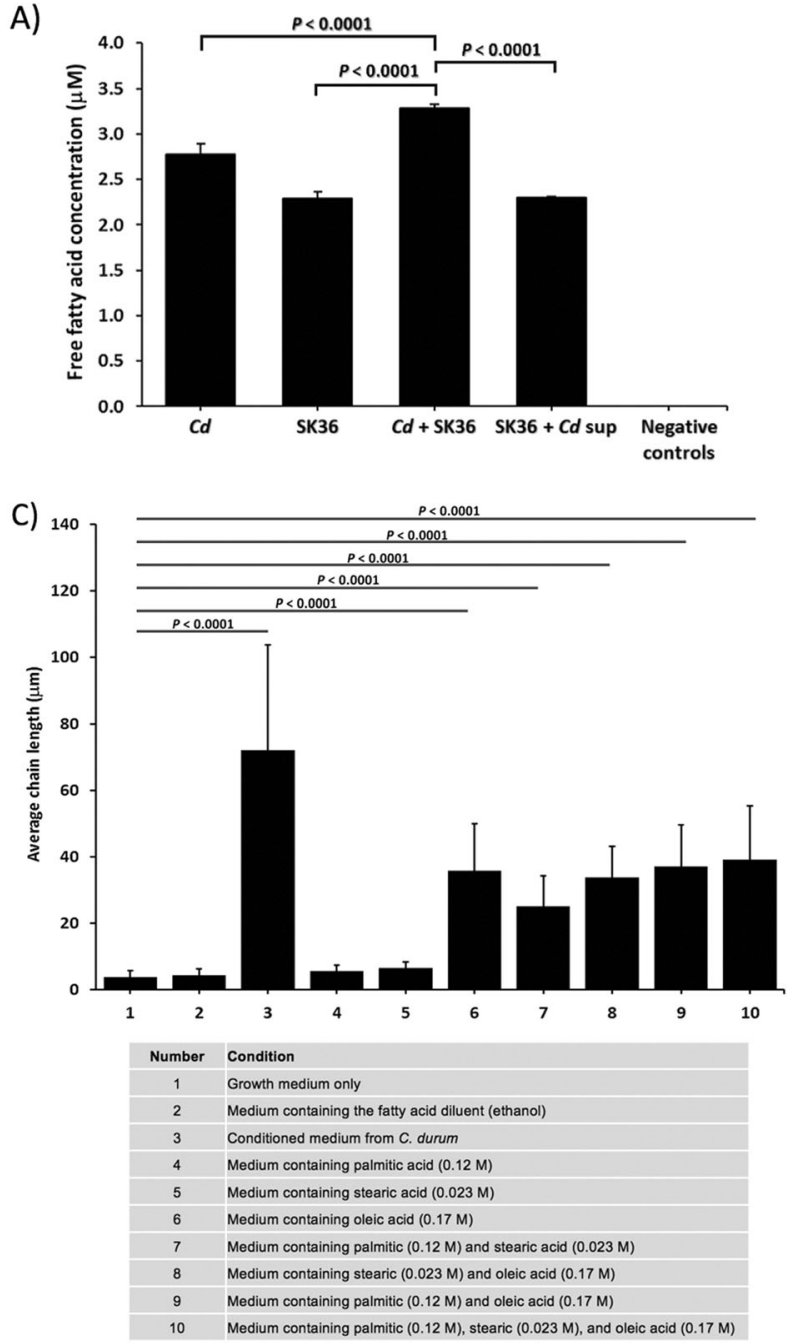

Fig. 3 Role of fatty acids in $S$. sanguinis chain elongation. a Comparison of free fatty acids $(\mu \mathrm{M})$ produced from $C d$, SK36, the mixed culture between $C d$ and SK36 $(C d+\mathrm{SK} 36)$ and $C d$-supernatant treated SK36 (SK36 $+C d$ sup). b Identification of the fatty acids present in $C d$ supernatants ( $C d$ sup) grown in defined medium. Palmitic acid (C16:0), stearic acid (C18:0), and oleic acid (C18:1) are increased in $C d$ sup compared with the medium control. c Effect of palmitic acid (C16:0), stearic acid, (C18:0), and/or oleic acid (C18:1) on SK36 chain length. SK36 was treated overnight with: 1. Growth medium only, 2. Medium containing the fatty acid diluent (ethanol), 3 . Conditioned medium from $C d, 4$. Medium containing palmitic acid

to induce the elongated phenotype as SK36 chain length showed no significant difference (Fig. 5a, b). However, when treating SK36 with $C$. durum JJ1 BHI glu supernatant, the elongated phenotype was restored (Fig. 5a). The impact of glucose on $C$. durum $\mathrm{JJ} 1$ fatty acid production was next determined. The amount of free fatty acids in $C$. durum JJ1 BHI and BHI glu supernatants showed a significant increase when compared with BHI w/o (Fig. 5c). These findings confirmed an important role of glucose in $C$. durum $\mathrm{JJ} 1$ fatty acids production.

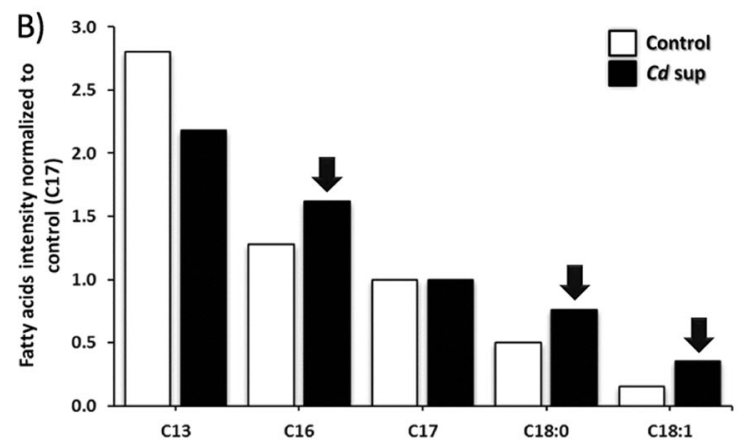

D)
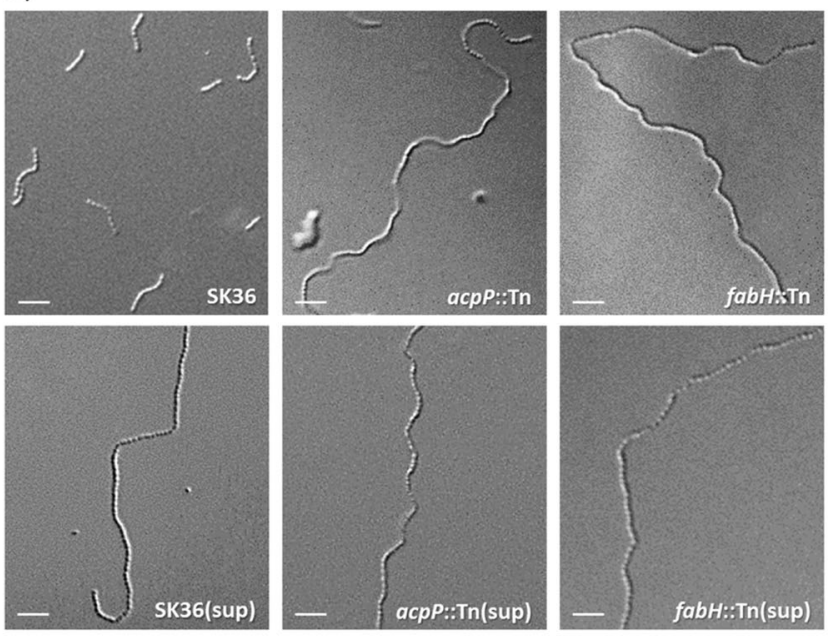

$(0.12 \mathrm{M})$, 5. Medium containing stearic acid $(0.023 \mathrm{M})$, 6. Medium containing oleic acid $(0.17 \mathrm{M}), 7$. Medium containing palmitic $(0.12$ $\mathrm{M})$ and stearic acid $(0.023 \mathrm{M}), 8$. Medium containing stearic $(0.023 \mathrm{M})$ and oleic acid $(0.17 \mathrm{M}), 9$. Medium containing palmitic $(0.12 \mathrm{M})$ and oleic acid $(0.17 \mathrm{M})$, and 10 . Medium containing palmitic $(0.12 \mathrm{M})$, stearic $(0.023 \mathrm{M})$, and oleic $(0.17 \mathrm{M})$ acid. Bacterial chain length was measured and calculated as described previously. Data are presented as the means \pm standard deviations. d Chain length of SK36 in comparison to its mutants $\triangle f a b H$ and $\triangle a c p P$ after treatment with $C d$ supernatant (sup) and the BHI control. The pictures are representative of three independent experiments. Scale bars indicate $10 \mu \mathrm{m}$.

\section{C. durum JJ1 membrane vesicles induce SK36 chain elongation}

MVs have been demonstrated as an important carrier for delivering a wide range of macromolecules in a concentrated and protected manner, including proteins, carbohydrates, lipids, nucleic acids, and toxins [58]. To learn if $C$. durum $\mathrm{JJ} 1$ produces $\mathrm{MVs}, C$. durum $\mathrm{JJ} 1$ culture supernatants were collected, filtered, and concentrated. By utilizing negative staining TEM analysis, we observed the 
A)

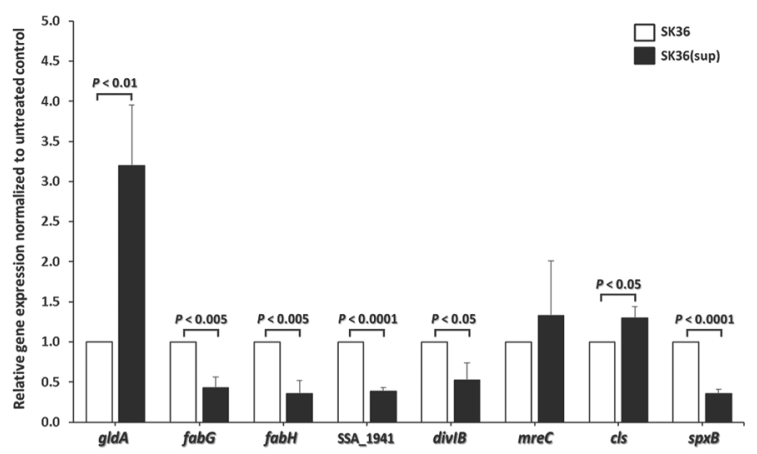

B)
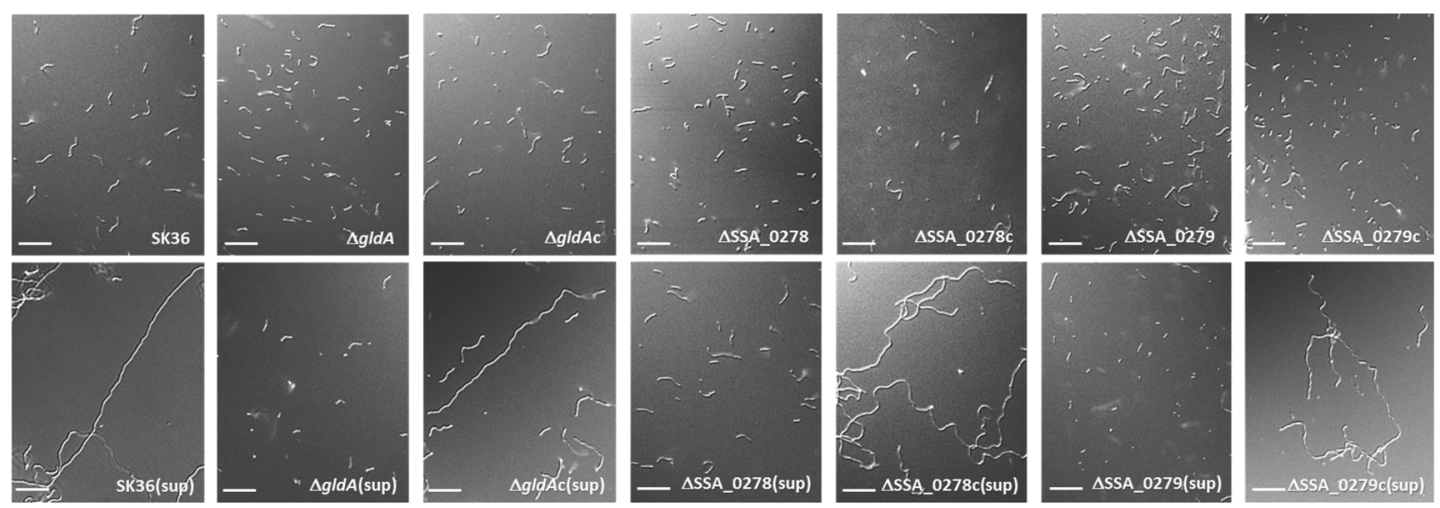

C)

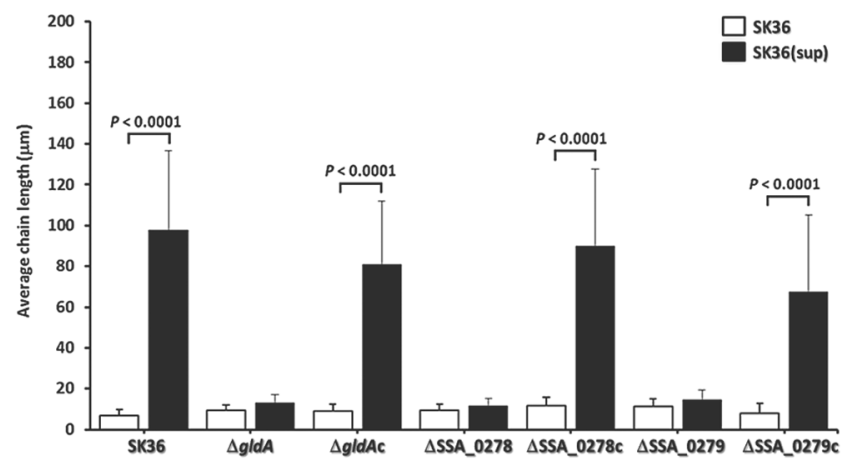

D)

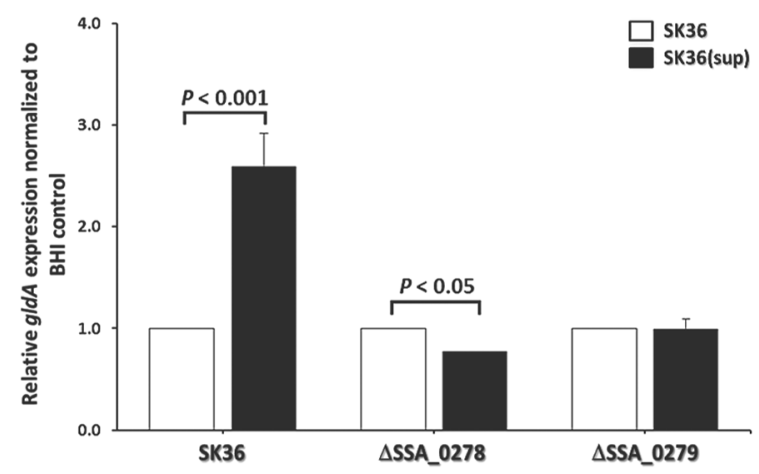

Fig. 4 Involvement of SK36 lipid metabolism and cell division genes in the elongated chain phenotype induced by $\boldsymbol{C d}$. a The expression of key SK36 FASII and cell division genes was quantified by qRT-PCR in SK36 grown to early exponential phase in $C d$ supernatants compared with the BHI control. b Bacterial chain morphology and (c) average chain length $(\mu \mathrm{m})$ of the wild-type SK36, the deletion mutants ( $\triangle$ gldA, $\triangle$ SSA_0278, and $\Delta$ SSA_0279), and the complemented (SgldAc, $\Delta$ SSA_0278c, and $\Delta$ SSA_0279c) strains

presence of spherical, double-walled vesicle-like structures confirming the presence of MVs (Fig. S4). After diluting the crude MVs preparation with 1X PBS 1:10, different sizes of spherical, double-walled vesicle-like structures were clearly visible (Fig. 6a). Interestingly, an obvious change in the morphology of the MVs occurred when samples were isolated from $C$. durum $\mathrm{JJ} 1$ grown in BHI w/o glucose (Fig. S4). The size of the spherical, double-walled vesicle- after being treated with $C d$ supernatants (sup) compared with BHI. The pictures are representative of three independent experiments. Scale bars indicate $10 \mu \mathrm{m}$. d The expression of gldA in the wild-type and the $\Delta$ SSA_0278 and $\Delta$ SSA_0279 deletion mutant strains was compared in the presence of $C d$ supernatants (sup) versus BHI. Gene expression data are presented relative to the BHI control samples, which were arbitrarily assigned a value of 1 . Data represent the means of three biological replicates. Error bars denote standard deviations.

like structures was substantially smaller than the ones isolated from BHI supernatants (Fig. S4 and 6a). Moreover, we observed a number of mini spherical, single-walled vesicle-like structures in glucose-free medium whereas none was identified in the BHI supernatant (Fig. 6a). These findings, at least in part, suggested that $C$. durum $\mathrm{JJ} 1$ is able to produce distinct MVs, and glucose can directly affect MV production. Further supporting the production of MVs, 
Fig. 5 Influence of glucose on the SK36 chain elongated phenotype. a Supernatants derived from different $C d$ culture conditions (BHI [BHI], $\mathrm{BHI}$ without glucose [BHI w/o], and $\mathrm{BHI}$ without glucose supplemented with $0.01 \mathrm{M}$ glucose [BHI glu]) were used to compare their effects upon SK36 chain lengths. b Bacterial chain length was measured and evaluated as described in "Materials and Methods". c Impact of glucose on $C d$ fatty acid production. Data presented as the means of three biological replicates. Error bars denote standard deviations. The pictures are representative of the independent experiments. Scale bars indicate $10 \mu \mathrm{m}$.
A)

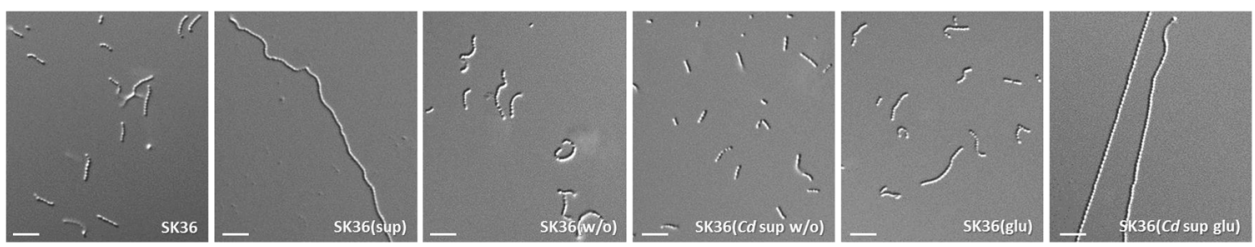

B)

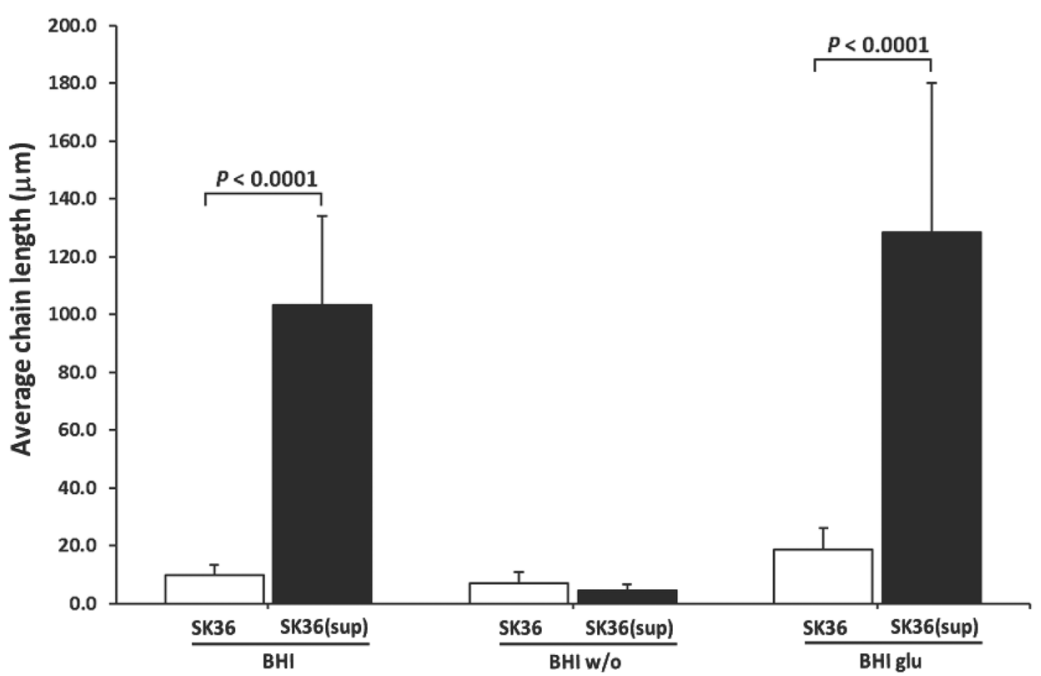

C)

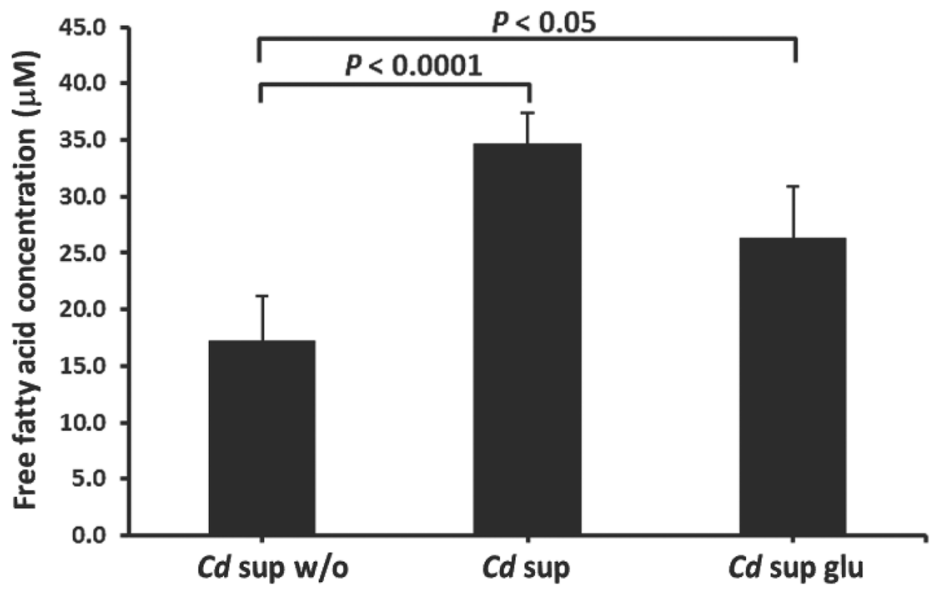

when $C$. durum $\mathrm{JJ} 1$ was grown as biofilm, a number of spherical, vesicle-like structures were also observed on the surfaces of bacterial cells (Fig. 6b).

Given that $C$. durum $\mathrm{JJ} 1$ supernatant in BHI was able to induce SK36 chain elongation whilst the supernatant in BHI w/o was not, we further investigated if the MVs isolated from $C$. durum JJ1 supernatants retained such an ability. MVs isolated from $C$. durum $\mathrm{JJ} 1$ in BHI were able to induce the elongated phenotype, especially in the 75 and $100 \% \mathrm{MV}$ preparations (Fig. 6c). In contrast, none of the MV preparations isolated from $C$. durum $\mathrm{JJ} 1$ in glucose-free medium was able to induce SK36 chain elongation (Fig. 6c). By assessing free fatty acid concentration in both MVs sample sets, MVs isolated from $C$. durum $\mathrm{JJ} 1$ supernatants in $\mathrm{BHI}$ revealed significantly higher free fatty acid content compared with BHI w/o $(P<0.005)$ (Fig. 6d). These findings strongly demonstrated an effect of glucose on $C$. durum JJ1 fatty acid production, contributing to SK36 chain elongation induction.

\section{C. durum JJ1 promotes SK36 fitness}

Given the ability of $C$. durum $\mathrm{JJ} 1$ to naturally cohabitate with $S$. sanguinis in the oral cavity [4], it was hypothesized that $C$. durum JJ1 may have a beneficial effect on $S$. sanguinis fitness in the oral cavity. To test this, $C$. durum JJ1 and SK36 were co-cultured and the number of viable bacterial cells $\left(\mathrm{CFU} \mathrm{ml}{ }^{-1}\right.$ ) assessed in comparison with single 
A)
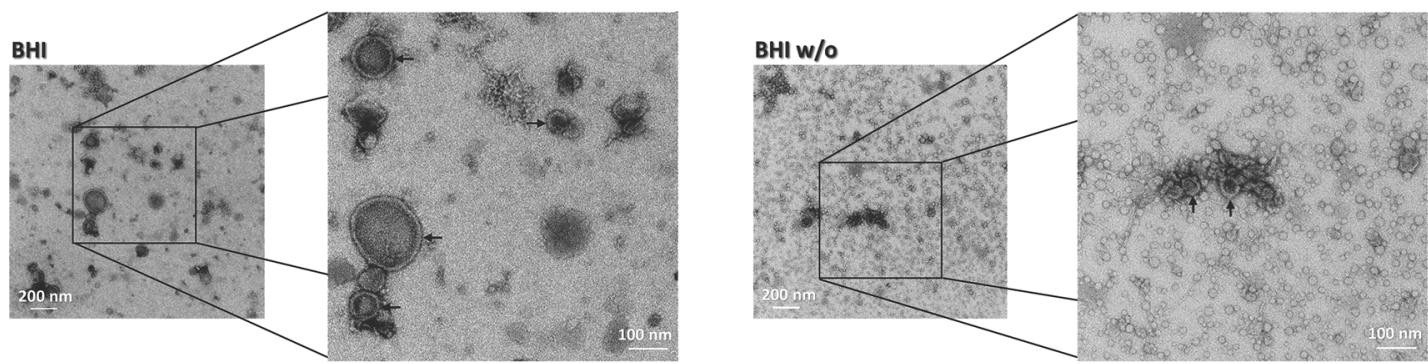

B)

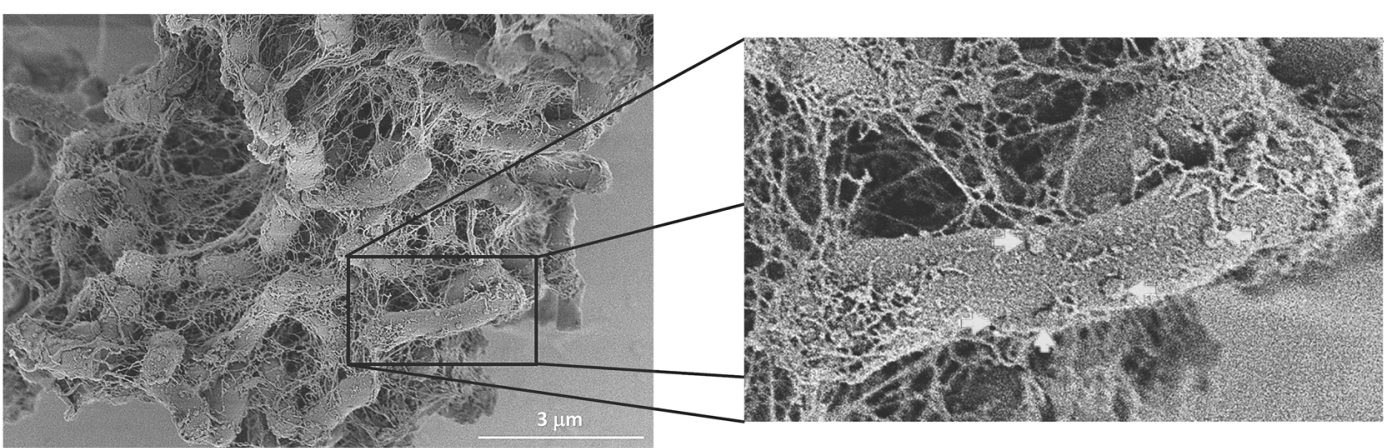

C)
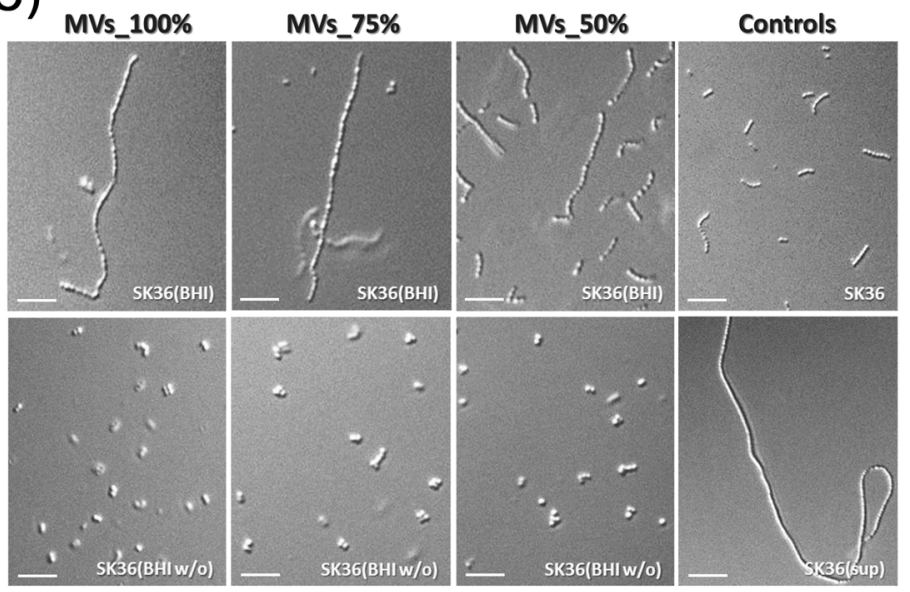

D)

Fig. 6 Transmission electron micrograph of MVs prepared from $\boldsymbol{C d}$. a 1:10-diluted samples in low and high magnification isolated from $C d$ grown in BHI (left) and BHI w/o (right), showing the differences of double-walled vesicle-like structures. Arrows indicate spherical MVs. b SEM image of $C d$ cells cultured in biofilm conditions showing spherical blebs (arrows) surrounding the bacteria. The pictures are representative of three independent experiments. Scale species controls. On day 1 (D1), it was apparent that $C$. durum JJ1 was able to substantially promote the SK36 growth, as the SK36 cell number in the co-cultured sample resulted in a 5-fold increase from its corresponding monospecies culture $(P<0.001)$ (Fig. 7a). Interestingly, growing $C$. durum JJ1 with SK36 significantly decreased $C$. durum $\mathrm{JJ} 1$ viable cell numbers (Fig. 7b). In contrast to D1, bacterial cell number in the co-cultured sample exhibited no significant difference from the individual cultures on both day 2 (D2) (Fig. 7a, b) and day 3 (D3) (data not shown) bars are indicated on each panel. c SK36 chain length morphology after being treated with MVs prepared from $C d$ grown in $\mathrm{BHI}$ and $\mathrm{BHI}$ w/o compared with $C d$ supernatants (sup) and the BHI controls. d Average chain length $(\mu \mathrm{m})$. Data are presented as the means of three biological replicates. Error bars denote standard deviations. Scale bars indicate $10 \mu \mathrm{m}$.

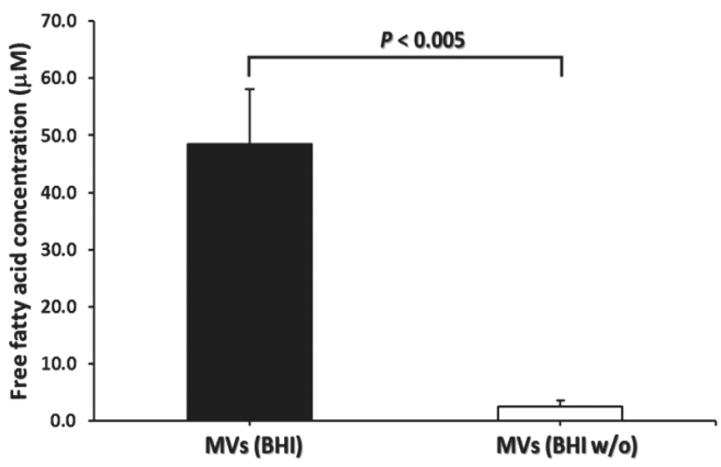

mainly caused by the overall decline of bacterial viability in batch cultures. This finding supports that $C$. durum JJ1 influences SK36 physiology and promotes its fitness.

\section{Effect of C. durum-S. sanguinis co-incubation on phagocytosis}

Bacterial chain length has been demonstrated to have an impact on phagocytosis susceptibility [59,60]. Given that C. durum JJ1 produces MVs to induce SK36 chain 
A)

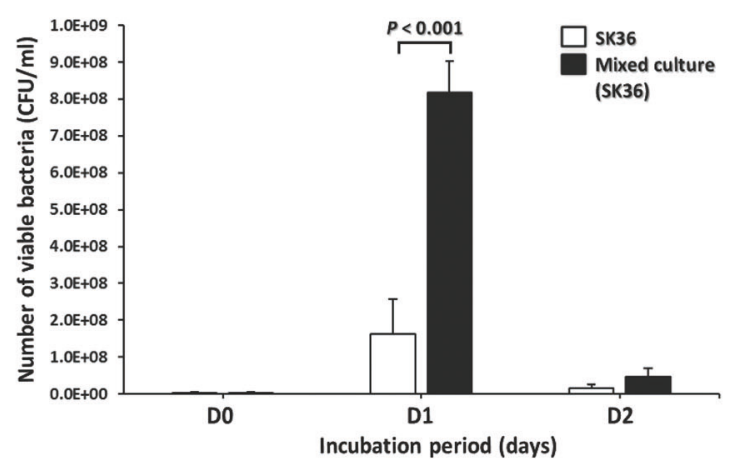

C)

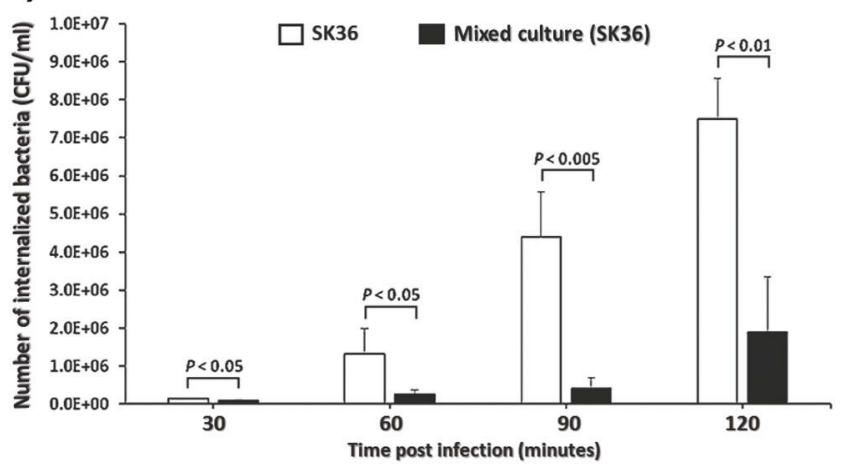

E)
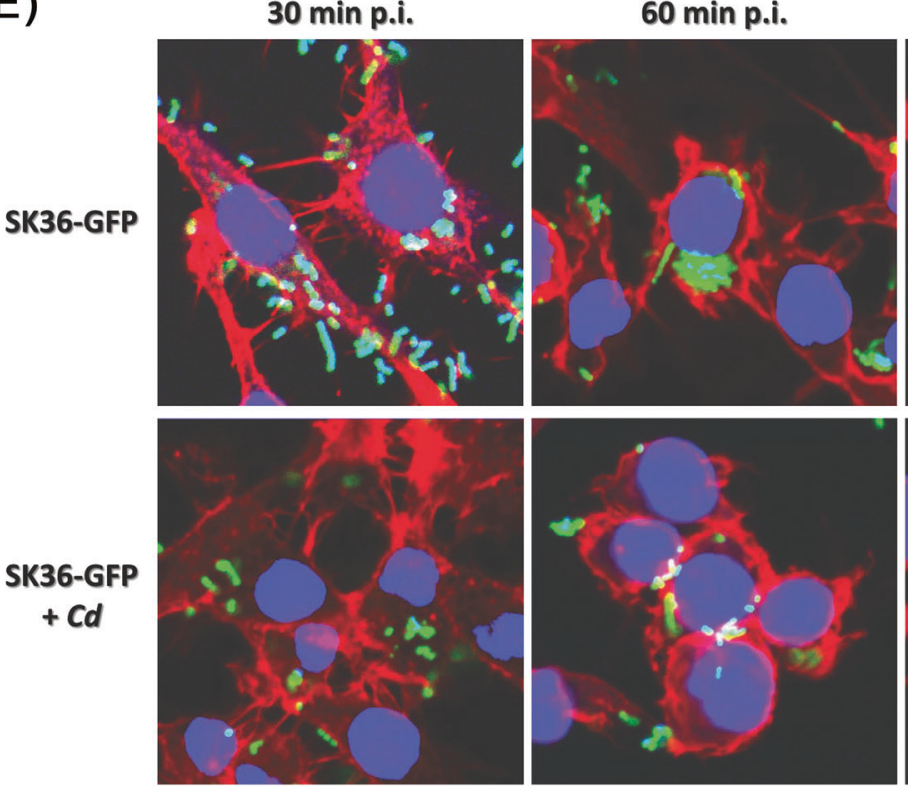

B)

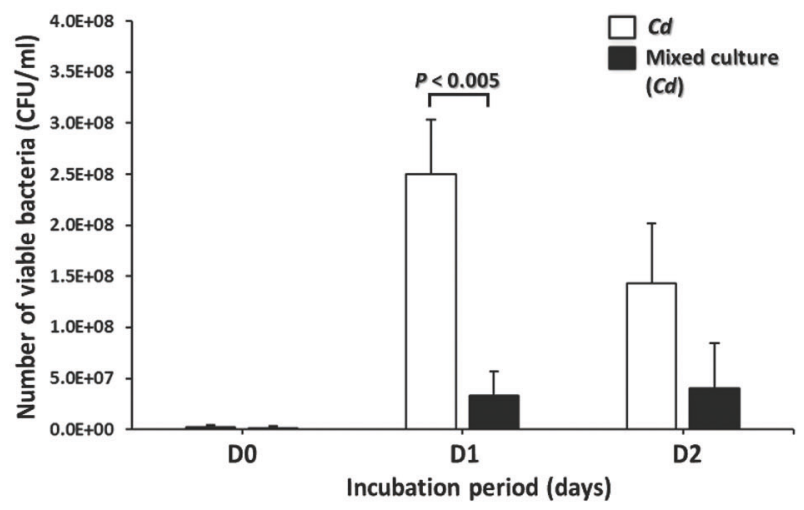

D)

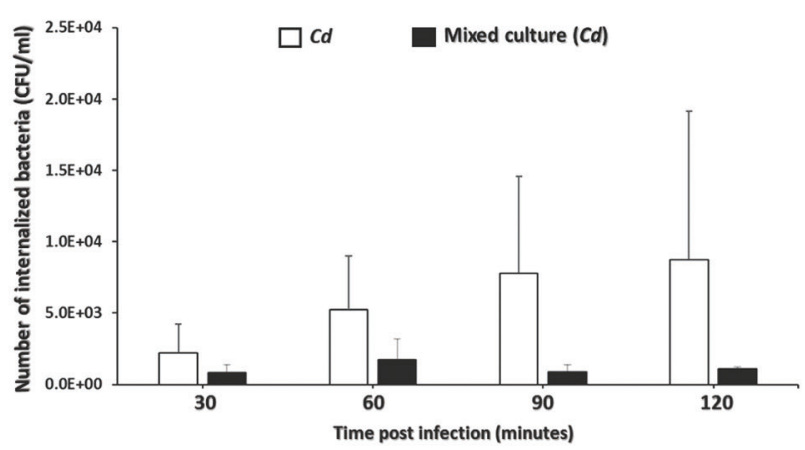

90 min p.i.
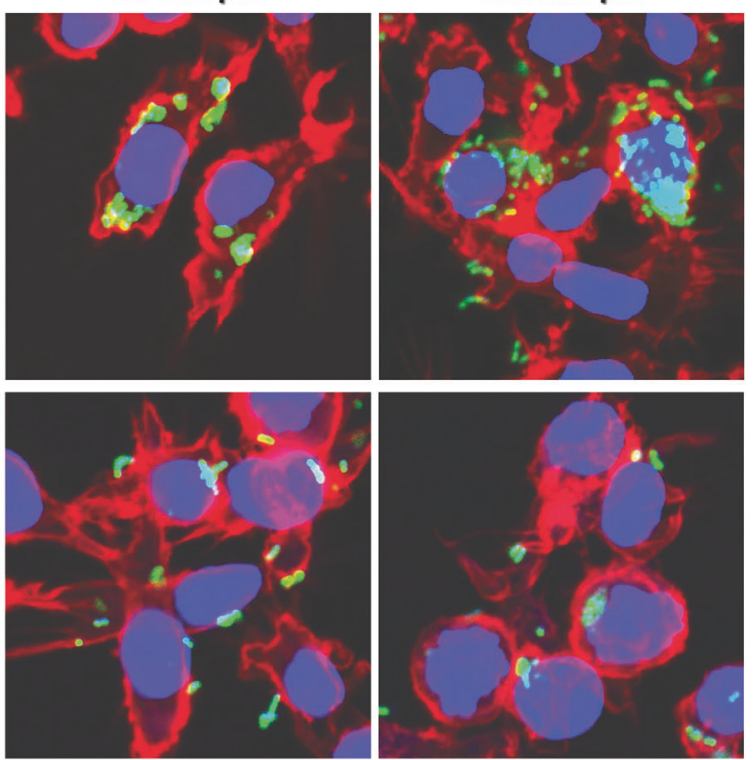

Fig. 7 Effect of $\boldsymbol{C d}$ on SK36 survivability and phagocytosis. (a) SK36 and (b) $C d$ viable cell counts $\left(\mathrm{CFU} \mathrm{ml}{ }^{-1}\right.$ ) after culturing either in mixed or monospecies cultures. Bacterial survival (CFU ml-1) within RAW 264.7 cells for up to $2 \mathrm{~h}$ post uptake of (c) SK36 and (d) $\mathrm{Cd}$, in the mixed culture compared with their individual culture controls. e Representative confocal micrographs of RAW 264.7 cells infected with SK36 expressing GFP (SK36-GFP) and its mixed culture with $C d(\mathrm{SK} 36-\mathrm{GFP}+C d)$ at $30,60,90$, and $120 \mathrm{~min}$ post uptake. Filamentous actin is indicated by red fluorescence, while nuclei are labeled with blue fluorescence. Data are presented as the means of three biological replicates. Error bars denote standard deviations. 
elongation, we initially attempted to investigate if elongated SK36 could also impact phagocytosis. However, we were unable to prepare elongated SK36 after $C$. durum JJ1 coincubation due to the disruption of cell chains following centrifugation, washing, and resuspension. Nonetheless, we were interested in the potential interference of phagocytosis. Murine macrophage-like RAW 264.7 cells, as phagocytic cells, were challenged with mixed cultures of SK36 and $C$. durum JJ1 in comparison with the single culture controls. At 30, 60, 90, and 120 min p.i., infected RAW 264.7 cells were lysed, and the number of viable bacteria $\left(\mathrm{CFU} \mathrm{ml}{ }^{-1}\right)$ was enumerated. The amount of phagocytosed SK36 from mixed cultures was approximately twofold to fourfold lower than that of SK36 monospecies cultures $(P<0.05)$ at all time points (Fig. 7c). In contrast, there was no significant differences in the numbers of $C$. durum $\mathrm{JJ} 1$ phagocytosed from mixed and monospecies cultures (Fig. 7d). Interestingly, $C$. durum $\mathrm{JJ} 1$ was internalized at much lower rates compared with SK36. To verify a decrease in SK36 numbers as observed in Fig. 7c, RAW 264.7 cells were challenged with SK36 expressing GFP (SK36-GFP) and immune-fluorescence staining was performed to visualize bacterial cells (green), RAW 264.7 cells actin (red), and nucleus structures (blue). In agreement with the CFU data, the confocal images revealed a decrease in the amount of phagocytosed SK36-GFP over 30, 60, 90, and 120 min p.i. when RAW 264.7 cells were challenged with SK36-GFP from mixed cultures with $C$. durum JJ1 (Fig. 7e). In contrast, an increase in the amount of phagocytosed SK36 at all four time points was observed when RAW 264.7 cells were challenged with monospecies SK36-GFP cultures (Fig. 7e). We were next curious whether the phagocytosis phenotype observed in the $S$. sanguinis- $C$. durum co-cultures is specific to $S$. sanguinis or could also be replicated using other streptococci. An uptake assay was performed by challenging RAW 264.7 cells with mixed cultures of $C$. durum JJ1 and S. mutans UA159 (Sm) or S. pyogenes M4 (Spy). Unlike what was demonstrated with SK36 (Fig. 7c), the $C$. durum JJ1 cultures mixed with Sm or Spy exhibited no significant differences in the number of phagocytosed streptococci at all time points (Fig. S5), indicating a specific interspecies, and beneficial interaction between $C$. durum and S. sanguinis.

In addition to impacting phagocytosis, bacterial chain morphology has been shown to impact cell aggregation [60]. Thus, a bacterial cell autoaggregation assay was performed as described previously [44, 61], and presented as an autoaggregation percentage $(\mathrm{Ag} \%)$. C. durum JJ1 supernatant treated SK36 (SK36[sup]) exhibited an 20fold increase $(P<0.01)$ in $\mathrm{Ag} \%$ compared with the BHI treated SK36 control (SK36) (Fig. S6). We next examined if $\mathrm{Ag} \%$ is affected by bacterial density by performing autoaggregation assay with 1:5, 1:10, and 1:20 bacterial cell dilutions. Although $\mathrm{Ag} \%$ in the three different dilutions of the cell suspension revealed marginal differences, these were not statistically significant suggesting that the here used dilutions did not affect the observed autoaggregation when SK36 is treated with $C$. durum JJ1 supernatant (Fig. S6). In summary, the experimental data suggests that bacterial chain length morphology impacts autoaggregation activity of SK36.

\section{Discussion}

Our interest in the interaction between Corynebacterium and Streptococcus spp. is the result of a recent publication revealing the close association of both genera within in situ dental plaques [4]. Both Corynebacterium and Streptococcus spp. are abundant genera in the supra-gingival biofilm [4], suggesting a prominent role in oral community organization. Their physical organization is most likely shaped by coaggregation and/or co-adhesion through specific surface protein interactions [9, 14, 62]. However, whether this association mediates specific interspecies interactions between the organisms was unknown.

Here we show that the production of MVs by $C$. durum can influence the cell chain length of $S$. sanguinis leading to a stronger autoaggregation of elongated of SK36 after being cultured in $C$. durum $\mathrm{JJ} 1$ supernatant. The initial colonizer S. sanguinis was chosen due to its relative high abundance in dental plaque. MV formation by Gram-negative and Gram-positive bacteria is known to play a crucial role in mediating cell-cell interactions for symbiotic and pathogenic relationships [63]. In our study, we isolated MVs from $C$. durum $\mathrm{JJ} 1$ supernatants which contain, at least in part, free fatty acids. If the free fatty acids are contained inside the vesicles or are associated with the vesicles is not known at this time. We also verified that isolated $C$. durum JJ1 MVs as well as fatty acids alone can induce SK36 chain elongation. MVs are generally diffusible, thus do not require close contact to confer the elongated chain phenotype, as we demonstrated with the transwell experiments. Interestingly, when we checked the growth of fluorescently labeled SK36 in freshly collected saliva, we detected a similar elongated chain length phenotype (Fig. S7). Whether this is due to the presence of Corynebacterium MV is speculative, but, nonetheless, shows that longer chain length seems to be the relevant growth phenotype for $S$. sanguinis in its natural environment.

Commensal bacteria have evolved with the host and a protective function for the host has been attributed to oral biofilm homeostasis [14, 64]. Here, we demonstrated an interesting relationship between oral commensals and the host immune system. We chose RAW 264.7 cells which have been used to model innate immune responses in the 
oral cavity [39, 40, 65]. When challenging RAW 264.7 cells, only the dual-species cultures of $C$. durum $\mathrm{JJ} 1$ and SK36 showed a significant decrease in bacterial phagocytosis, whereas the dual-species cultures of $C$. durum JJ1 with $S$. mutans or $S$. pyogenes showed no differences. This suggests that $C$. durum exerts a species-specific protective function over $S$. sanguinis to avoid significant inhibition by the host innate immunity. The protective effect seems to extent also towards killing by macrophages, since cocultured $S$. sanguinis showed increased resistance against killing when incubated in lysates of RAW 264.7 cells (Fig. S10). From an ecological perspective, the observed benefit from the interaction between Corynebacterium and $S$. sanguinis might aid in their health supportive mission. Both species have been shown to be abundant in the healthy individuals, and biogeographical studies showed that they build a base at the gingival margin, with $S$. sanguinis also occupying other parts of the exposed tooth [4]. How is the avoidance of phagocytosis beneficial for both species and the host? Injuries to the gingival margin followed by rapid wound healing process involving the recruitment of proinflammatory macrophages are common [66-68]. Furthermore, other phagocytic leukocytes can be recruited through the release of macrophage migration inhibitory factor, which is constitutively expressed in oral epithelial cells as a central regulator of wound healing responsible for host against infections [69]. Thus, it is intriguing to speculate that the inflammatory response at the injury area can discriminate between bacterial species that have by themselves a protecting function to the host avoiding futile elimination of commensal species. S. sanguinis is also less susceptible than other streptococci to various innate immunity mechanisms such complement opsonization and IgG binding, further supporting its assignment as a health-associated commensal in the oral biofilm $[14,70]$. However, we were unable to directly test how chain elongation affects phagocytosis, since $S$. sanguinis cells could not be reliably prepared maintaining long chains for the phagocytosis assay. Therefore, the effect of $C$. durum on $S$. sanguinis phagocytosis seems to be independent of the cell length, but chain elongation can further influence phagocytosis efficiency as shown for $S$. mutans $[59,71]$.

The regulation of the elongated chain phenotype seems to involve a metabolic coordination of fatty acid production in S. sanguinis. S. sanguinis is able to adjust its own fatty acid synthesis by the external supply of fatty acids provided by $C$. durum. The $f a b$ operon, encoding key steps in fatty acid biosynthesis, is significantly downregulated when $S$. sanguinis is grown in $C$. durum supernatants. Similarly, deletion of $f a b H$ or $a c p P$ in $S$. sanguinis resulted in a similar chain length phenotype even without growth in C. durum supernatants (Fig. 3d). FabT functions as a transcriptional repressor of the fatty acid biosynthetic enzymes $(f a b)$ gene cluster, and a $S$. pneumoniae strain that lacks FabT in the genome appears to have an elongated chain length phenotype $[45,46]$. Given that both $S$. pneumoniae FabT and S. sanguinis SSA_1941 share $78 \%$ amino acid identity, it could potentially verify the elongated phenotype of SK36 acpP::Tn and $f a b H::$ Tn (Fig. 3d) and the effect on $f a b$ gene expression (Fig. 4a) as shown in this study. Nonetheless, the exact role of both genes in fatty acid metabolism requires further studies. Interestingly, we also observed a significant increase in the expression of gldA, encoding gldA, which converts glycerol into glycerone (dihydroxyacetone). Glycerol is a metabolite connecting glycerolipid metabolism with central metabolism/ glycolysis. In agreement with the increased expression of gldA in S. sanguinis, a deletion of gldA or its predicted transcriptional regulators encoded by SSA_0278 and SSA_0279 renders the cells unable to form longer chains when grown in $C$. durum supernatants. This suggests that the metabolic interaction between both species is quite sophisticated and might also influence central metabolism. How glycerol metabolism plays into the interaction of both species is currently under investigation.

The functional role of commensal Corynebacterium spp. is not well investigated, but a common theme is emerging implicating a health-supporting function of these organisms. Likewise, interspecies interactions of Corynebacterium spp. seem to influence microbial community composition. This is evident from a recent study demonstrating that nostril pneumococcal colonization in children is inversely correlated to the abundance of Corynebacterium spp. Thus, abundant colonization by Corynebacterium spp. might prevent or delay pneumococcal colonization [72]. The molecular basis for this inverse relationship was identified in a study using $C$. accolens, a common commensal of the nasopharynx [73]. C. accolens is able to modify its local environment by releasing antibacterial free fatty acids from the host epithelium that inhibit pneumococcal growth. Corynebacterium spp. influence on other bacterial species can also be more direct by specifically interfering with their pathogenicity. Such an interaction was demonstrated between C. striatum and Staphylococcus aureus [74]. Dualspecies incubation triggered a decreased transcription of genes associated with $S$. aureus virulence and elevated expression of genes that would allow colonization, thus reprogramming $S$. aureus into a more commensal state. Our results are also supporting the unique beneficial and commensal role of Corynebacterium spp. as a significant, yet understudied species able to influence the host environment. The ability of Corynebacterium spp. to interact with other species seems to include a variety of mechanisms, MVs being one of them and might vary depending upon the respective Corynebacterium spp., the interaction partner(s), and the host environment. 
Our study demonstrates the importance of dual and multispecies models to study bacterial behaviors. Elongated cell chains appear to be the norm for S. sanguinis when present in saliva and our assay system provides an effective method to replicate this behavior in vitro. In addition, the functional interaction between both species may support stable commensal communities, possibly inhibiting competition or displacement from the ecological niche by cariogenic species. Further studies of interspecies synergism between oral corynebacteria and streptococci will likely reveal even more complex ecological interactions that are central for maintaining symbiosis with the microbiota and ultimately oral health.

Acknowledgements This work was supported by an NIH-NIDCR grant DE021726 to JK and NIH-NIDCR grants DE018893 and DE022083 to JM. We thank Prof. Todd Kitten for kindly providing $S$. sanguinis SK strains, Dr Stefanie K. Petrie (Advanced Light Microscopy Core, OHSU) for expert assistance with LSM 780 confocal microscope, Prof. Dennis Koop (Bioanalytical Shared Resource/ Pharmacokinetics Core, OHSU) for fatty acid identification, Dr Claudia S. López (Multiscale Microscopy Core, OHSU) for expert assistance in performing TEM with technical support from Center for Spatial Systems Biomedicine (OCSSB). We also thank Dr Nyssa Cullin for constructing SK36 ldh-gfp.

\section{Compliance with ethical standards}

Conflict of interest The authors declare that they have no conflict of interest.

Publisher's note Springer Nature remains neutral with regard to jurisdictional claims in published maps and institutional affiliations.

\section{References}

1. The Human Microbiome Project C, Huttenhower C, Gevers D, Knight R, Abubucker S, Badger JH, et al. Structure, function and diversity of the healthy human microbiome. Nature. 2012;486:207.

2. Dewhirst FE, Chen T, Izard J, Paster BJ, Tanner ACR, Yu W-H, et al. The human oral microbiome. J Bacteriol. 2010;192:5002-17.

3. Ribeiro AA, Azcarate-Peril MA, Cadenas MB, Butz N, Paster BJ, Chen $\mathrm{T}$, et al. The oral bacterial microbiome of occlusal surfaces in children and its association with diet and caries. Plos ONE. 2017;12:e0180621

4. Mark Welch JL, Rossetti BJ, Rieken CW, Dewhirst FE, Borisy GG. Biogeography of a human oral microbiome at the micron scale. Proc Natl Acad Sci. 2016;113:E791.

5. Xiao C, Ran S, Huang Z, Liang J. Bacterial diversity and community structure of supragingival plaques in adults with dental health or caries revealed by $16 \mathrm{~S}$ pyrosequencing. Front Microbiol. 2016;7: Article 1145.

6. Wang K, Lu W, Tu Q, Ge Y, He J, Zhou Y, et al. Preliminary analysis of salivary microbiome and their potential roles in oral lichen planus. Sci Rep. 2016;6:22943.

7. Tsai C-Y, Tang CY, Tan T-S, Chen K-H, Liao K-H, Liou M-L. Subgingival microbiota in individuals with severe chronic periodontitis. J Microbiol Immunol Infect. 2018;51:226-34.
8. Hsu SD, Cisar JO, Sandberg AL, Kilian M. Adhesive properties of viridans streptoccocal species. Microb Ecol Health Dis. 1994;7:125-37.

9. Egland PG, Palmer RJ, Kolenbrander PE. Interspecies communication in Streptococcus gordonii-Veillonella atypica biofilms: signaling in flow conditions requires juxtaposition. Proc Natl Acad Sci USA. 2004;101:16917-22.

10. Hannig C, Hannig M, Rehmer O, Braun G, Hellwig E, Al-Ahmad A. Fluorescence microscopic visualization and quantification of initial bacterial colonization on enamel in situ. Arch Oral Biol. 2007;52:1048-56.

11. Jakubovics NS, Yassin SA, Rickard AH. Chapter two-community interactions of oral streptococci. In: Sariaslani S, Gadd GM, editors. Advances in Applied Microbiology. vol. 87. Academic Press; Waltham, MA; 2014. p. 43-110.

12. Aas JA, Paster BJ, Stokes LN, Olsen I, Dewhirst FE. Defining the normal bacterial flora of the oral cavity. J Clin Microbiol. 2005;43:5721-32.

13. Paster BJ, Olsen I, Aas JA, Dewhirst FE. The breadth of bacterial diversity in the human periodontal pocket and other oral sites. Periodontology 2000.2006;42:80-7.

14. Kreth J, Merritt J, Qi F. Bacterial and host interactions of oral streptococci. DNA Cell Biol. 2009;28:397-403.

15. Kreth J, Giacaman RA, Raghavan R, Merritt J. The road less traveled - defining molecular commensalism with Streptococcus sanguinis. Mol Oral Microbiol. 2017;32:181-96.

16. Kreth J, Vu H, Zhang Y-M, Herzberg MC. Characterization of hydrogen peroxide-induced DNA release by Streptococcus sanguinis and Streptococcus gordonii. J Bacteriol. 2009;191:6281-91.

17. Zheng L, Itzek A, Chen Z, Kreth J. Environmental influences on competitive hydrogen peroxide production in Streptococcus gordonii. Appl Environ Microbiol. 2011;77:4318-28.

18. Slavkin HC. Biofilms, microbial ecology and Antonie van Leeuwenhoek. J Am Dent Assoc. 1997;128:492-5.

19. Kuramitsu HK, He X, Lux R, Anderson MH, Shi W. Interspecies interactions within oral microbial communities. Microbiol Mol Biol Rev. 2007;71:653-70.

20. Kreth J, Merritt J, Shi W, Qi F. Competition and coexistence between Streptococcus mutans and Streptococcus sanguinis in the dental biofilm. J Bacteriol. 2005;187:7193-203.

21. Ng HM, Kin LX, Dashper SG, Slakeski N, Butler CA, Reynolds EC. Bacterial interactions in pathogenic subgingival plaque. Microb Pathogenesis. 2016;94:60-9.

22. Riegel P, Heller R, Prevost G, Jehl F, Monteil H. Corynebacterium durum sp. nov., from human clinical specimens. Int J Syst Evolut Microbiol. 1997;47:1107-11.

23. Tsuzukibashi O, Uchibori S, Shinozaki-Kuwahara N, Kobayashi T, Takada K, Hirasawa M. A selective medium for the isolation of Corynebacterium species in oral cavities. J Microbiological Methods. 2014;104:67-71.

24. Tomoyasu T, Imaki H, Masuda S, Okamoto A, Kim H, Waite RD, et al. LacR mutations are frequently observed in Streptococcus intermedius and are responsible for increased intermedilysin production and virulence. Infect Immun. 2013;81:3276-86.

25. He X, Wu C, Yarbrough D, Sim L, Niu G, Merritt J, et al. The cia operon of Streptococcus mutans encodes a unique component required for calcium-mediated autoregulation. Mol Microbiol. 2008;70:112-26.

26. Taciak B, Białasek M, Braniewska A, Sas Z, Sawicka P, Kiraga Ł, et al. Evaluation of phenotypic and functional stability of RAW 264.7 cell line through serial passages. Plos ONE. 2018;13: e0198943.

27. Sambrook J, Fritsch EF, Maniatis T. Molecular cloning: a laboratory manual. Cold Spring Harbor, NY: Cold Spring Harbor Laboratory Press; 1989. p. 1546. 
28. Cullin N, Redanz S, Lampi KJ, Merritt J, Kreth J. Murein hydrolase LytF of Streptococcus sanguinis and the ecological consequences of competence development. Appl Environ Microbiol. 2017;83:e01709-17.

29. Zheng L, Chen Z, Itzek A, Ashby M, Kreth J. Catabolite control protein A controls hydrogen peroxide production and cell death in Streptococcus sanguinis. J Bacteriol. 2011;193:516-26.

30. Chen Z, Itzek A, Malke H, Ferretti JJ, Kreth J. Dynamics of speB mRNA transcripts in Streptococcus pyogenes. J Bacteriol. 2012;194:1417-26

31. Chen Z, Itzek A, Malke H, Ferretti JJ, Kreth J. Multiple roles of RNase $\mathrm{Y}$ in Streptococcus pyogenes mRNA processing and degradation. J Bacteriol. 2013;195:2585-94.

32. Lepage G, Roy CC. Improved recovery of fatty acid through direct transesterification without prior extraction or purification. J Lipid Res. 1984;25:1391-6.

33. Jensen SK. Improved Bligh and Dyer extraction procedure. Lipid Technol. 2008;20:280-1.

34. Bauman SJ, Kuehn MJ. Purification of outer membrane vesicles from Pseudomonas aeruginosa and their activation of an IL-8 response. Microbes Infect. 2006;8:2400-8.

35. Prados-Rosales R, Baena A, Martinez LR, Luque-Garcia J, Kalscheuer R, Veeraraghavan U, et al. Mycobacteria release active membrane vesicles that modulate immune responses in a TLR2dependent manner in mice. J Clin Investig. 2011;121:1471-83.

36. Prados-Rosales R, Weinrick BC, Piqué DG, Jacobs WR, Casadevall A, Rodriguez GM. Role for Mycobacterium tuberculosis membrane vesicles in iron acquisition. $\mathrm{J}$ Bacteriol. 2014;196:1250-6.

37. Lasica AM, Ksiazek M, Madej M, Potempa J. The type IX secretion system (T9SS): highlights and recent insights into its structure and function. Front Cell Infect Microbiol. 2017;7:215.

38. English BK, Patrick CC, Orlicek SL, McCordic R, Shenep JL. Lipoteichoic acid from viridans streptococci induces the production of tumor necrosis factor and nitric oxide by murine macrophages. J Infect Dis. 1996;174:1348-51.

39. Kim HY, Baik JE, Ahn KB, Seo HS, Yun C-H, Han SH. Streptococcus gordonii induces nitric oxide production through its lipoproteins stimulating Toll-like receptor 2 in murine macrophages. Mol Immunol. 2017;82:75-83.

40. Kim JS, Kim KD, Na HS, Jeong SY, Park HR, Kim S, et al. Tumor necrosis factor- $\alpha$ and interleukin- $1 \beta$ expression pathway induced by Streptococcus mutans in macrophage cell line RAW 264.7. Mol Oral Microbiol. 2012;27:149-59.

41. Kurosawa M, Oda M, Domon H, Isono T, Nakamura Y, Saitoh I, et al. Streptococcus pyogenes CAMP factor promotes calcium ion uptake in RAW264.7 cells. Microbiol Immunol. 2018;62:617-23.

42. van den Bogaart E, Mens PF, Adams ER, Grobusch MP, Schallig HDFH. Phagocytosis of hemozoin by RAW 264.7 cells, but not THP-1 cells, promotes infection by Leishmania donovani with a nitric oxide-independent mechanism. Parasitol Int. 2017;66:196-206.

43. Cullinane M, Gong L, Li X, Lazar-Adler N, Tra T, Wolvetang E, et al. Stimulation of autophagy suppresses the intracellular survival of Burkholderia pseudomallei in mammalian cell lines. Autophagy. 2008;4:744-53.

44. Evans K, Stone V, Chen L, Ge X, Xu P. Systematic study of genes influencing cellular chain length in Streptococcus sanguinis. Microbiology. 2014;160:307-15.

45. Lu Y-J, Rock CO. Transcriptional regulation of fatty acid biosynthesis in Streptococcus pneumoniae. Mol Microbiol. 2006;59:551-66.

46. Jerga A, Rock CO. Acyl-acyl carrier protein regulates transcription of fatty acid biosynthetic genes via the FabT repressor in Streptococcus pneumoniae. J Biol Chem. 2009;284:15364-8.
47. Faustoferri RC, Hubbard CJ, Santiago B, Buckley AA, Seifert TB, Quivey RG. Regulation of fatty acid biosynthesis by the global regulator CcpA and the local regulator FabT in Streptococcus mutans. Mol Oral Microbiol. 2015;30:128-46.

48. Fozo EM, Quivey RG. The fabM gene product of Streptococcus mutans is responsible for the synthesis of monounsaturated fatty acids and is necessary for survival at low $\mathrm{pH}$. J Bacteriol. 2004;186:4152-8.

49. Brinster S, Lamberet G, Staels B, Trieu-Cuot P, Gruss A, Poyart C. Type II fatty acid synthesis is not a suitable antibiotic target for Gram-positive pathogens. Nature. 2009;458:83.

50. Yao J, Rock CO. How bacterial pathogens eat host lipids: Implications for the development of fatty acid synthesis therapeutics. J Biol Chem. 2015;290:5940-6.

51. Noirclerc-Savoye M, Le Gouëllec A, Morlot C, Dideberg O, Vernet $\mathrm{T}$, Zapun A. In vitro reconstitution of a trimeric complex of DivIB, DivIC and FtsL, and their transient co-localization at the division site in Streptococcus pneumoniae. Mol Microbiol. 2005;55:413-24.

52. Le Gouëllec A, Roux L, Fadda D, Massidda O, Vernet T, Zapun A. Roles of pneumococcal DivIB in cell division. J Bacteriol. 2008;190:4501-11.

53. Ruch FE, Lin EC, Kowit JD, Tang CT, Goldberg AL. In vivo inactivation of glycerol dehydrogenase in Klebsiella aerogenes: properties of active and inactivated proteins. J Bacteriol. 1980;141:1077-85.

54. Ruzheinikov SN, Burke J, Sedelnikova S, Baker PJ, Taylor R, Bullough PA, et al. Glycerol dehydrogenase: structure, specificity, and mechanism of a family III polyol dehydrogenase. Structure. 2001;9:789-802.

55. Novichkov PS, Kazakov AE, Ravcheev DA, Leyn SA, Kovaleva GY, Sutormin RA, et al. RegPrecise 3.0 - a resource for genomescale exploration of transcriptional regulation in bacteria. BMC Genom. 2013;14:745.

56. Takeno S, Takasaki M, Urabayashi A, Mimura A, Muramatsu T, Mitsuhashi S, et al. Development of fatty acid-producing Corynebacterium glutamicum Strains. Appl Environ Microbiol. 2013;79:6776-83.

57. Pancholi V, Caparon MG. Streptococcus pyogenes metabolism. In: Ferretti JJ, Stevens DL, Fischetti VA, editors. Streptococcus pyogenes: basic biology to clinical manifestations. Oklahoma City, OK: University of Oklahoma Health Sciences Center; 2016. p. $1-62$.

58. Kulp A, Kuehn MJ. Biological functions and biogenesis of secreted bacterial outer membrane vesicles. Annu Rev Microbiol. 2010;64:163-84

59. Nakano K, Fujita K, Nishimura K, Nomura R, Ooshima T. Contribution of biofilm regulatory protein A of Streptococcus mutans, to systemic virulence. Microbes Infect. 2005;7:1246-55.

60. Dalia AB, Weiser JN. Minimization of bacterial size allows for complement evasion and is overcome by the agglutinating effect of antibody. Cell Host Microbe. 2011;10:486-96.

61. Merritt J, Niu G, Okinaga T, Qi F. Autoaggregation response of Fusobacterium nucleatum. Appl Environ Microbiol. 2009;75:7725-33.

62. van Leeuwen PT, van der Peet JM, Bikker FJ, Hoogenkamp MA, Oliveira Paiva AM, Kostidis S, et al. Interspecies interactions between Clostridium difficile and Candida albicans. mSphere. 2016;1:e00187-16.

63. Brown L, Wolf JM, Prados-Rosales R, Casadevall A. Through the wall: extracellular vesicles in Gram-positive bacteria, mycobacteria and fungi. Nat Rev Microbiol. 2015;13:620.

64. Bowen WH, Burne RA, Wu H, Koo H. Oral biofilms: pathogens, matrix, and polymicrobial interactions in microenvironments. Trends Microbiol. 2018;26:229-42. 
65. Croft AJ, Metcalfe S, Honma K, Kay JG. Macrophage polarization alters postphagocytosis survivability of the commensal Streptococcus gordonii. Infect Immun. 2018;86:e00858-17.

66. Szpaderska AM, Zuckerman JD, DiPietro LA. Differential injury responses in oral mucosal and cutaneous wounds. J Dent Res. 2003;82:621-6.

67. Wong JW, Gallant-Behm C, Wiebe C, Mak K, Hart DA, Larjava $\mathrm{H}$, et al. Wound healing in oral mucosa results in reduced scar formation as compared with skin: Evidence from the red Duroc pig model and humans. Wound Repair Regeneration. 2009;17:717-29.

68. Iglesias-Bartolome R, Uchiyama A, Molinolo AA, Abusleme L, Brooks SR, Callejas-Valera JL, et al. Transcriptional signature primes human oral mucosa for rapid wound healing. Sci Transl Med. 2018;10:eaap8798.

69. Calandra T, Roger T. Macrophage migration inhibitory factor: a regulator of innate immunity. Nat Rev Immunol. 2003;3: 791-800.
70. Alves LA, de Carli TR, Harth-Chu EN, Mariano FS, Höfling JF, Stipp RN, et al. Oral streptococci show diversity in resistance to complement immunity. J Med Microbiol. 2019;68:600-8.

71. Fujita K, Matsumoto-Nakano M, Inagaki S, Ooshima T. Biological functions of glucan-binding protein B of Streptococcus mutans. Oral Microbiol Immunol. 2007;22:289-92.

72. Laufer AS, Metlay JP, Gent JF, Fennie KP, Kong Y, Pettigrew MM. Microbial communities of the upper respiratory tract and otitis media in children. mBio. 2011;2:e00245-10.

73. Bomar L, Brugger SD, Yost BH, Davies SS, Lemon KP. Corynebacterium accolens releases antipneumococcal free fatty acids from human nostril and skin surface triacylglycerols. mBio. 2016;7:e01725-15.

74. Ramsey MM, Freire MO, Gabrilska RA, Rumbaugh KP, Lemon KP. Staphylococcus aureus shifts toward commensalism in response to Corynebacterium species. Front Microbiol. 2016;7:1230.

75. Schneider CA, Rasband WS, Eliceiri KW. NIH Image to ImageJ: 25 years of image analysis. Nat Methods. 2012;9:671. 